OPEN ACCESS

Edited by:

Xiaolei Wang,

University of Alberta, Canada

Reviewed by:

Zhenyu Xing,

South China Normal University, China

Fang Liu,

Stanford University, United States

Wook Ahn,

Soonchunhyang University, South

Korea

*Correspondence:

Kunfeng Chen

Kunfeng.Chen@sdu.edu.cn

Feng Liang

liangfeng@kmust.edu.cn

Dongfeng Xue

df.xue@siat.ac.cn

Specialty section: This article was submitted to

Electrochemistry,

a section of the journal

Frontiers in Chemistry

Received: 02 November 2021

Accepted: 10 December 2021

Published: 11 January 2022

Citation:

Sun X, Chen K, Liang F, Zhi C and Xue $D$ (2022) Perspective on Micro-

Supercapacitors.

Front. Chem. 9:807500.

doi: $10.3389 /$ fchem.2021.807500

\section{Perspective on} Micro-Supercapacitors

\author{
Xiangfei Sun ${ }^{1}$, Kunfeng Chen ${ }^{1 *}$, Feng Liang ${ }^{2 *}$, Chunyi Zhi ${ }^{3}$ and Dongfeng Xue ${ }^{4 *}$ \\ ${ }^{1}$ Institute of Novel Semiconductors, State Key laboratory of Crystal Material, Jinan, China, ${ }^{2}$ State Key Laboratory of Complex Non- \\ ferrous Metal Resources Clean Application, Faculty of Metallurgical and Energy Engineering, Kunming University of Science and \\ Technology, Kunming, China, ${ }^{3}$ Department of Materials Science and Engineering, City University of Hong Kong, Kowloon, China, \\ ${ }^{4}$ Multiscale Crystal Materials Research Center, Shenzhen Institute of Advanced Technology, Chinese Academy of Sciences, \\ Shenzhen, China
}

The rapid development of portable, wearable, and implantable electronic devices greatly stimulated the urgent demand for modern society for multifunctional and miniaturized electrochemical energy storage devices and their integrated microsystems. This article reviews material design and manufacturing technology in different micro-supercapacitors (MSCs) along with devices integrate to achieve the targets of their various applications in recent years. Finally, We also critically prospect the future development directions and challenges of MSCs.

Keywords: micro-supercapacitors, integrated device, electrode materials, health monitoring, wearable electronic device

\section{INTRODUCTION}

The ongoing development of small electronic devices for telecommunication, microelectromechanical systems, and biomedical/environmental applications is creating a great demand for energyautonomous systems (Shen et al., 2013; Li et al., 2016; Zhang et al., 2017a; Soam et al., 2017). Among many electrochemical energy accumulators such as lithium-ion batteries, fuel cells and supercapacitors (SCs), SCs have been widely studied by researchers due to their advantages such as fast charging and discharging speed, long cycle life and high power density (Wang et al., 2020a; Chen et al., 2020; Kumar et al., 2021; Wang et al., 2021). SCs, including electrochemical double-layer capacitors (EDLCs) and pseudocapacitors, show lower energy storage capability (ES $\leq 10 \mathrm{~W} \mathrm{~h} \mathrm{~kg}{ }^{-1}$ ) compared to batteries $\left(\mathrm{ES} \sim 180 \mathrm{~W} \mathrm{~h} \mathrm{~kg}^{-1}\right.$ ). While SCs can be achieved a higher-power density ( $10 \mathrm{~kW}$ $\mathrm{kg}^{-1}$ ) (Guo et al., 2017; Chatterjee and Nandi, 2021). However, the shape of the device is greatly limited due to the unbending of the electrodes of traditional SCs. Moreover, the preparation of the electrodes involves metal collectors and binders, which also reduces the electrochemical performance of the SCs. Therefore, the development of a flexible and small supercapacitor matching with portable electronic products has become the development direction of the next generation of energy storage devices.

Micro-supercapacitors (MSCs) are the primary choice for advanced miniaturized energy storage devices due to their adequate power density and maintain a fast frequency response. In general, MSCs are sandwiched structures with sizes ranging from a few microns to centimetres. Thus, electrochemical properties available MSCs largely depend on the loading capacity and dispersion state of the active nano or micron particles. Compared with traditional rigid and bulky structures, their one-dimensional structures have various advantages (Zhai et al., 2020a):1) they have higher mechanical flexibility (which helps to withstand long-term and repetitive deformation); 2) Allow easy self-integration extension (which achieves the targets of their various applications); 3) Easy to fit into small spaces of different shapes (this brings versatility of the design); 4) It has the shape advantage of integrating with other one-dimensional devices (preferably for manufacturing multi-functional wearable systems). 


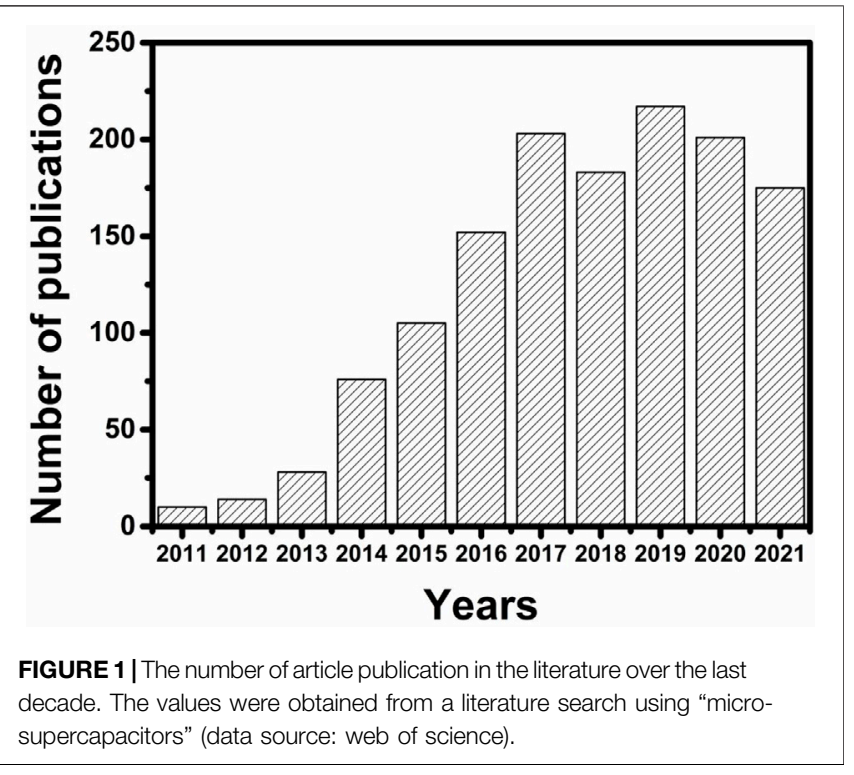

A

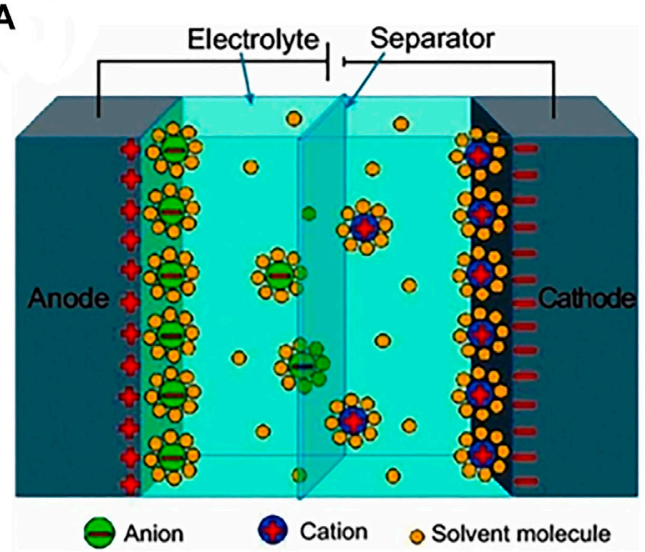

C

EDLC

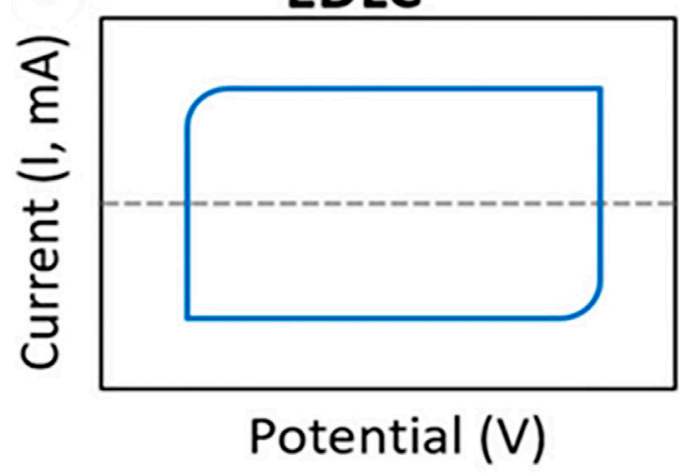

Figure 1), there is still a great need for comprehensive reviews in time to introduce the latest developments in this exciting field. This article gives a comprehensive overview of the research progress of miniature SCs in the past severe years. First, the classification of SCs is briefly discussed. Next, the material design and manufacturing technology of MSCs in recent years are introduced. After these parts, it focuses on the latest progress in medical diagnosis with MSC. Finally, it summarizes the future development and existing problems of MSCs.

\section{CLASSIFICATION OF SUPERCAPACITORS}

SCs are defined as an electrochemical capacitor device have received greatest attention nowadays. According to previous literatures, the SCs have important features such as long life span (>10 5 cycles) (Lu et al., 2017; Kumar et al., 2019; Zhai et al., 2020b) and higher energy density than electrochemical energy storage devices, and higher power density (5-15 kW

\section{B}

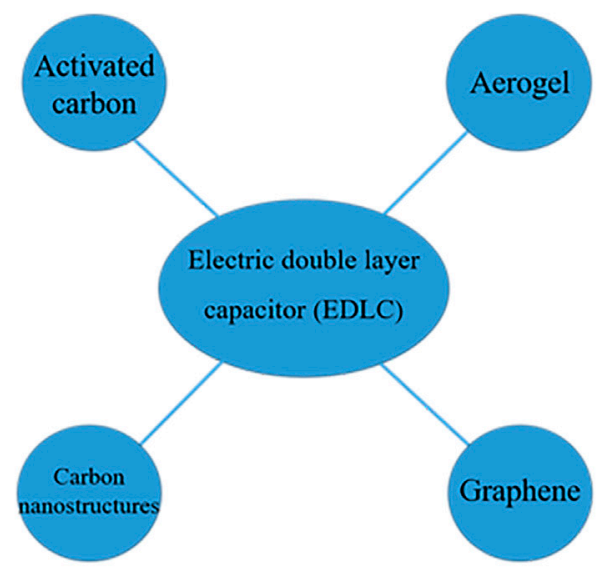

D

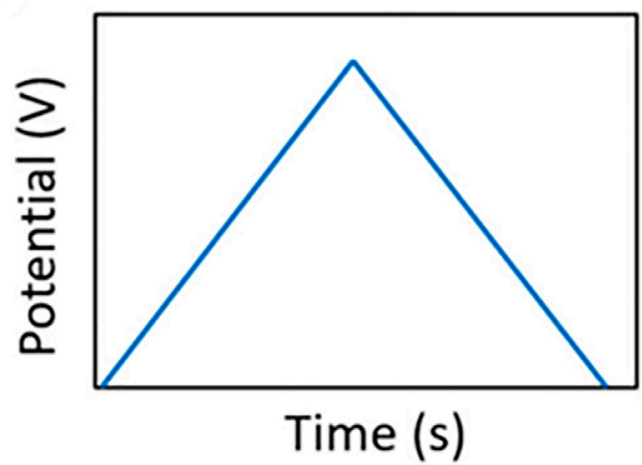

FIGURE 2 | Schematic diagram (A) (Chen et al., 2017), material classification (B), CV (C) and GCD (D) characteristic curves of EDLC (Jiang and Liu, 2019).

In the past few decades, the research on MSCs has developed rapidly and made great progress. Although some special aspects of MSCs can be found in the literature (as shown in $\mathrm{kg}^{-1}$ ) (Guo et al., 2017) as compared to battery and fuel cell. On the basis of charge storage mechanism, the SCs are be divided into two types including the pseudocapacitors 

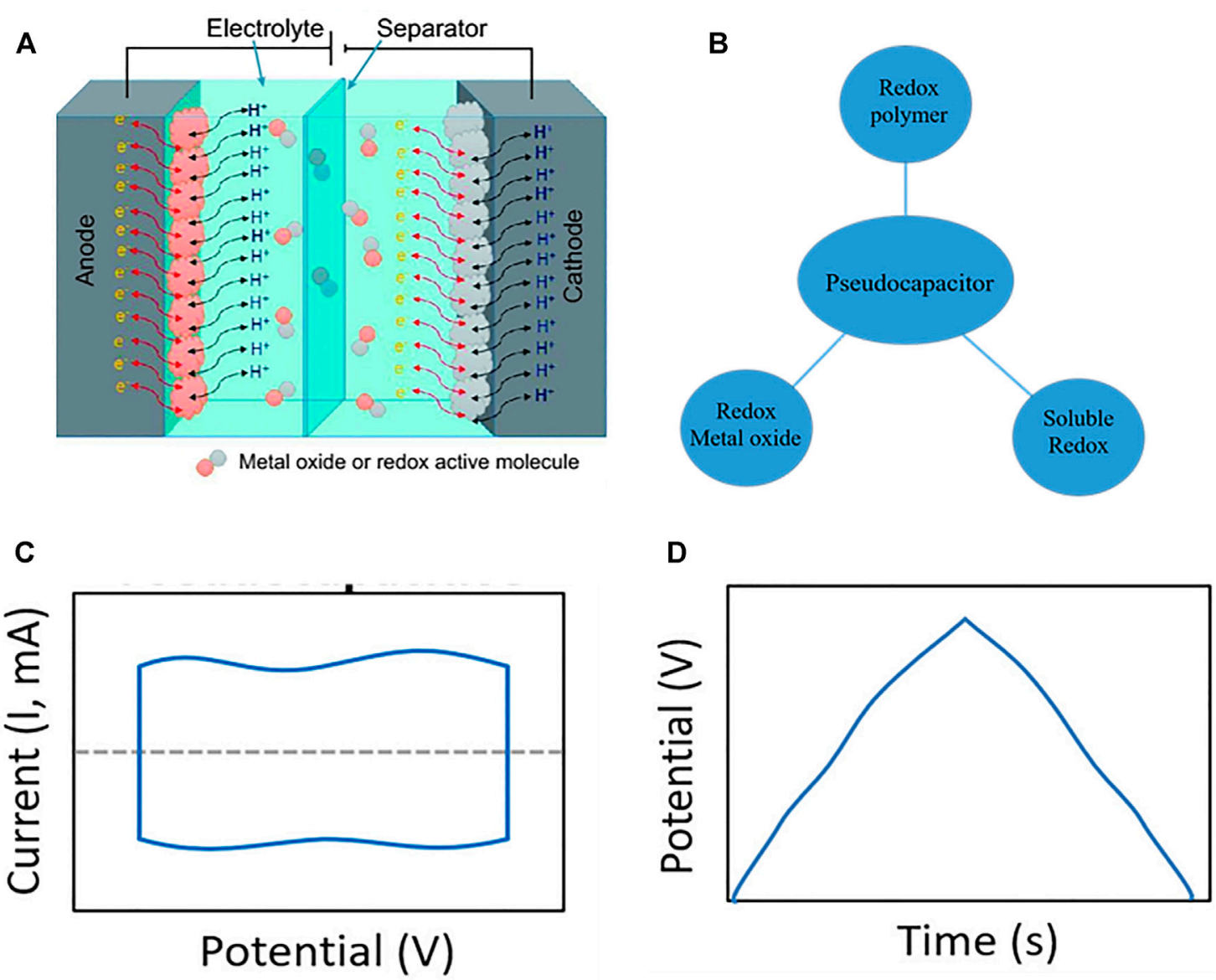

FIGURE 3 | Schematic diagram (A) (Chen et al., 2017), material classification (B), CV (C) and GCD (D) characteristic curves of pseudocapacitor (Jiang and Liu, 2019).

and electric double layer capacitors (EDLCs) (Arbizzani et al., 1996; Hwang and Hyun, 2007; Miller et al., 2018; Seol et al., 2020).

The EDLC uses the electric double layer interface formed between the electrode and the electrolyte to store charge (Morimoto et al., 1996; Zhang et al., 2009; Shao et al., 2020), and its structure is shown in Figure 2A. The separator separates the two electrodes. During charging, positive and negative charges accumulate on the surface of the two electrodes to form a capacitance. The accumulated charge during discharge returns to the electrolyte and generates a discharge current in the external circuit. At present, the electrode materials of a mainly include activated carbon (Wei et al., 2012; Wei and Yushin, 2012; Lei et al., 2013; Mori et al., 2019), carbon nanotubes (Zhou et al., 2014; Wang et al., 2016; Chang et al., 2018; Kshetri et al., 2018), carbon nanofiber (Liao et al., 2020), graphene (Kim et al., 2020; Wong et al., 2020), carbon materials (Xing et al., 2015; Xing et al., 2018) and aerogel (Fang and Binder, 2006; Zhang et al., 2006; Liu et al., 2018a), which have the characteristics of high conductivity, high strength, corrosion resistance, and high temperature resistance Figure 2B. The cyclic voltammogram (CV) curve
(Figure 2C) and the galvanostatic charge/discharge (GCD) curve (Figure 2D) of the response of the EDLC exhibit rectangular and triangular shapes, respectively.

The capacitance of a pseudocapacitor comes from the oxidation-reduction reaction between the electrode material and the electrolyte. The electrode material is mainly metal oxide, metal-doped carbon and conductive polymer. Its structure is shown in Figure 3A (Chen et al., 2017). Electron transfer occurs during the capacitance generation process of pseudocapacitors. Although the electrochemical behavior is different from pure EDLCs, it is also different from batteries. Generally, redox polymer (Zhang et al., 2017b; Boota and Gogotsi, 2019; Witomska et al., 2019; Choudhary et al., 2021), redox metal oxide (Jiang et al., 2012; Chen et al., 2014a; Lee et al., 2016; Salunkhe et al., 2017; Wang et al., 2019) and soluble redox show pseudocapacitance (Figure 3B). The capacitance of a pseudocapacitor has a high degree of dynamic reversibility, and its CV curve (Figure 3C) presents a rectangular shape with redox peaks, which is a typical capacitive characteristic. The GCD curve (Figure 3D) has a charging and discharging platform. 
A

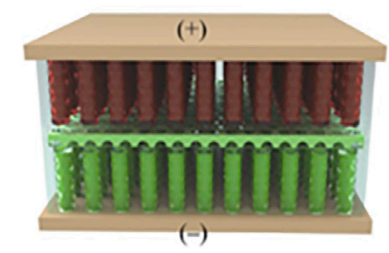

Sandwich stacked type

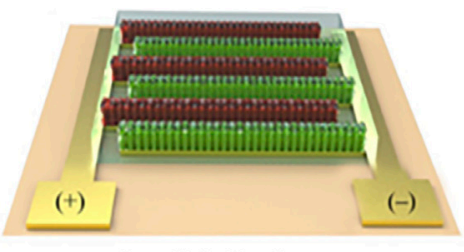

Interdigital in-plane type
B

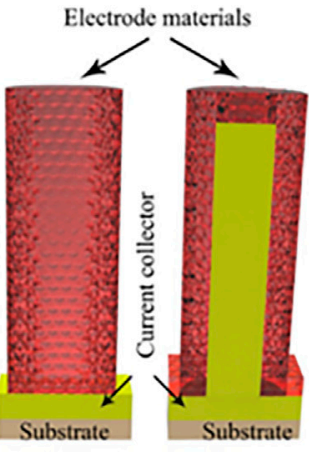

Homogeneous Heterogencous electrode unit electrode unit

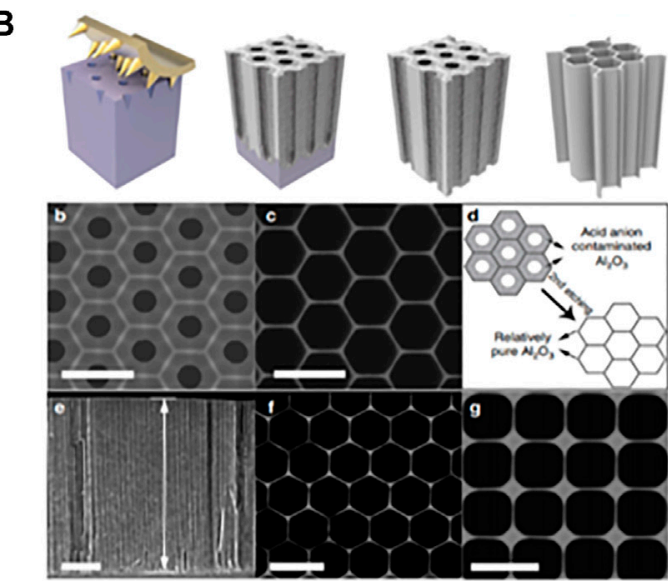

C

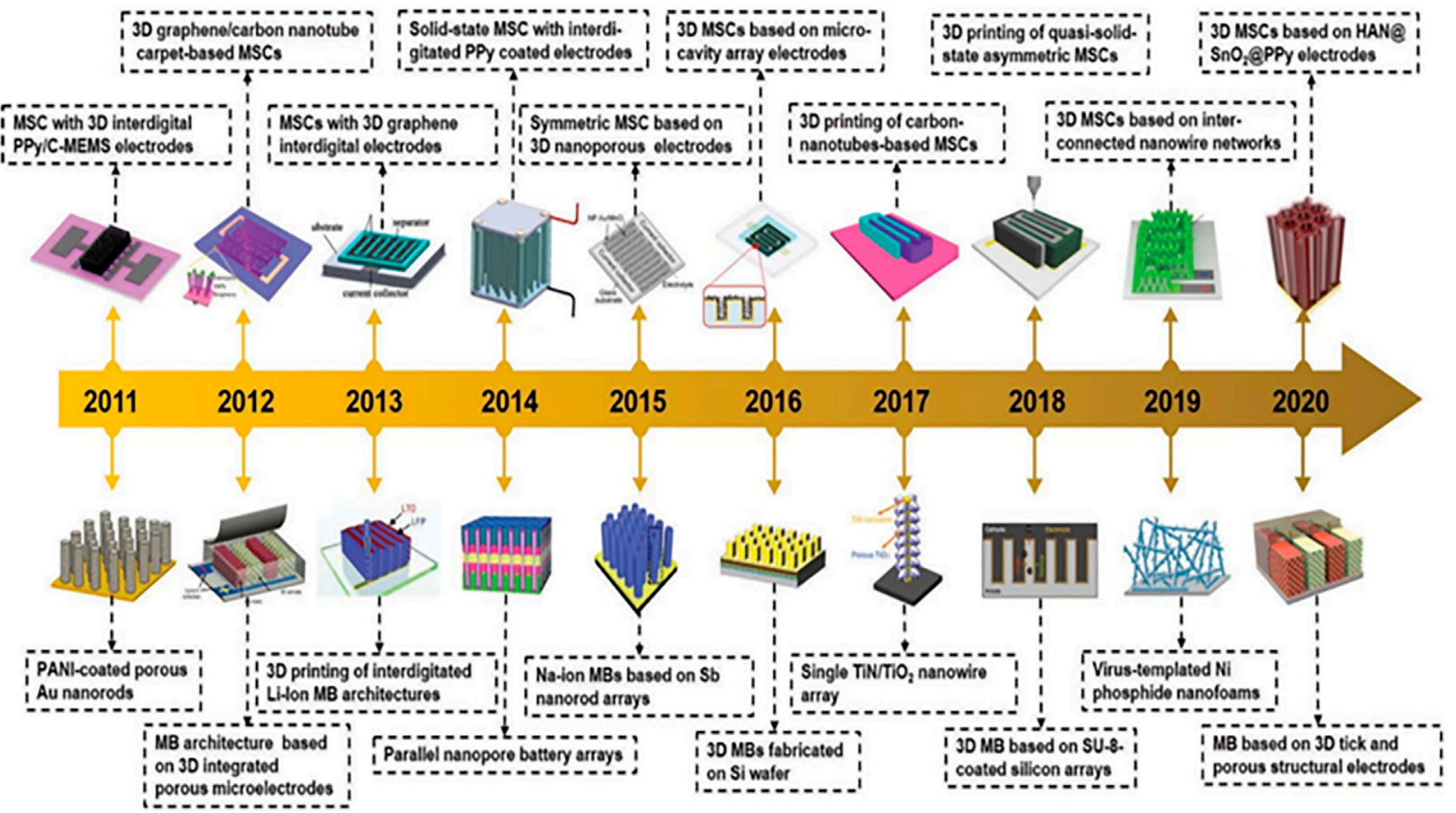

FIGURE 4 | Schematic of 3D MSCs (A) (Liu et al., 2019a), Brief development featuring representative 3D architecture electrodes for MSCs (B) (Lei et al., 2020), Fabrication and structure of HAN (C) (Sha et al., 2021).

Novel electrochemical energy storage technologies with enhanced energy capacity, and power capability are urgently needed. Supercapatteries can combine the merits of rechargeable batteries and SCs into one device (Archana et al., 2020; Yu and Chen, 2020). Recently, Xue et al. have developed colloidal supercapattery, which include colloidal electrode that can perform multiple-electron redox reactions and fast ion diffusion leaded to ultrahigh specific capacitance and fast charge rate (Chen et al., 2014b; Chen et al., 2015a; Chen et al., 2015b; Chen and Xue, 2017; Chen and Xue, 2018). Colloidal electrode materials include multiple varying ion forms, multi-interaction and abundant redox active sites. Colloidal electrode can skip over the material synthesis process to construct high-performance supercapattery. By only designing redox ions, the electrochemical performance of colloidal electrode is corresponding programmed. various redox cations with different oxidation states have shown promising application in colloidal supercapatteries, i.e. $\mathrm{V}^{3+}$, $\mathrm{Mn}^{2+}, \mathrm{Fe}^{3+}, \mathrm{Co}^{2+}, \mathrm{Ni}^{2+}, \mathrm{Cu}^{2+}, \mathrm{Sn}^{4+}, \mathrm{Ce}^{3+}, \mathrm{Yb}^{3+}$ and $\mathrm{Er}^{3+}$ ions (Chen et al., 2013; Chen et al., 2014c; Chen et al., 2014d; Chen et al., 2015c; Liang et al., 2018).

Due to its ultrahigh power density $\left(>10 \mathrm{~mW} \mathrm{~cm}{ }^{-2}\right)$, long lifespan ( $\geq 100000$ cycles), and remarkable mechanical flexibility, MSCs are recognized as the preferred miniaturized energy technology for a variety of autonomous electronic components (Zhao et al., 2017; Liu et al., 2019a; Bi 

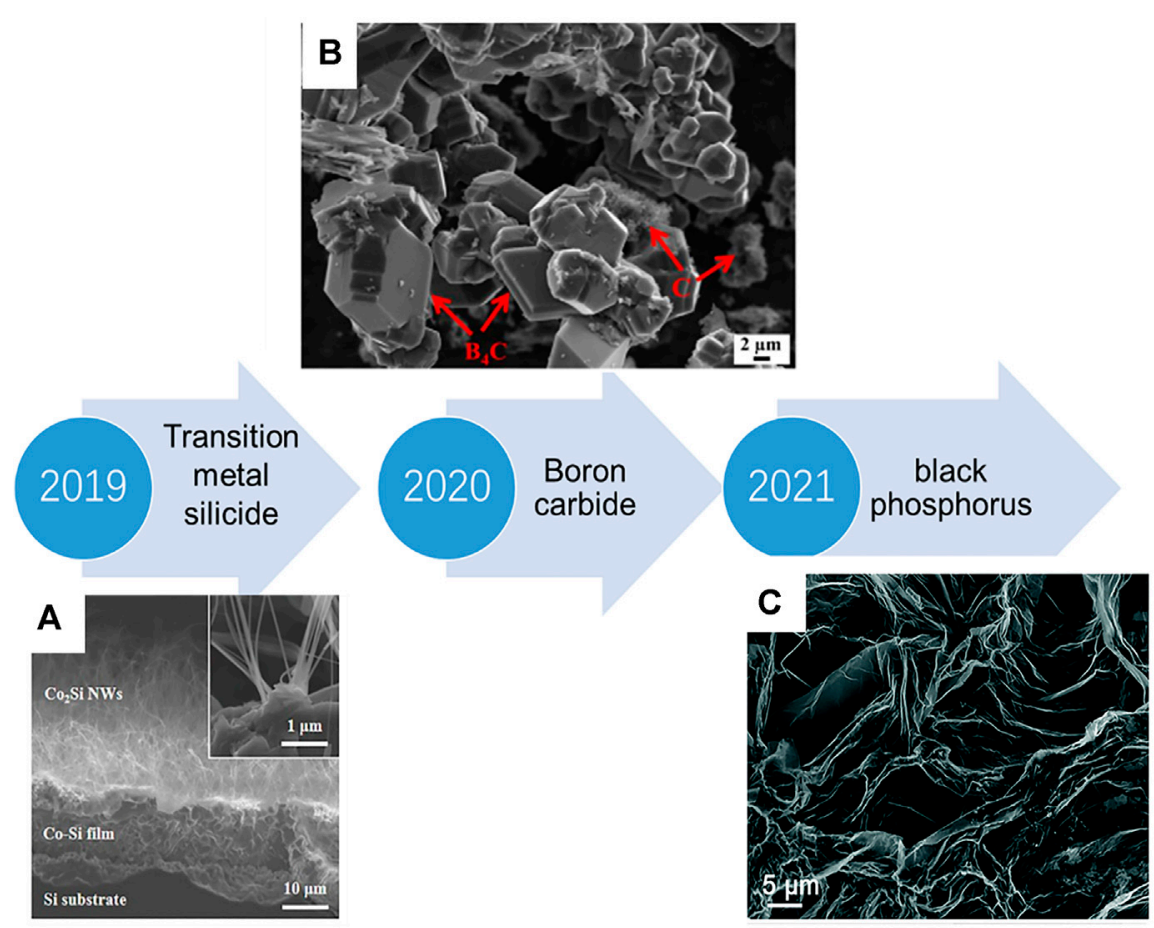

FIGURE 5 | A brief timeline of the developments of promising of MSCs (In et al., 2008; Balcı et al., 2021; Yang et al., 2021a).

et al., 2019). Figure 4A presents the 3D MSCs electrodes with sandwich and interdigital structure, respectively. Owing to the unique three-dimensional architectures (3D), 3D materials typically have a large specific surface area $\left(>1,000 \mathrm{~m}^{2} \mathrm{~g}^{-1}\right)$, which favors the accessibility of ion-active sites as well as improved ion and electron transport, hence facilitating reaction kinetics (Zhao et al., 2018a; Liu et al., 2019b; Lochmann et al., 2018). 3D MSCs have received a lot of attention in the last decade because of the obvious improved electrochemical performance of conventional SCs using 3D architecture electrodes, with the goal of developing micropower sources that meet both the dimensional and energetic requirements for on-chip integration (Figure 4C) (Sha et al., 2021). Particularly, significant progress has been made in the design and manufacturing of 3D architectural electrodes for the development of 3D MSCs (Liu et al., 2018b; Zhao et al., 2018b; Zhao and Lei, 2020). Lei et al. (Figure 4B) have designed the cell size of honeycomb monoliths (HMs) to the nanoscale, allowing for greater freedom in nanostructure design beyond their capacity for broad applications in many sectors (Lei et al., 2020). To avoid the formation of dense clusters of nanowires and nanotubes with high aspect ratios while meeting the criteria of high specific surface area and rapid ion transport dynamics, the cell size of conventional honeycomb monoliths should be decreased to the nanoscale level. Therefore, fabrication of microminiaturized cellular monomers-honeycomb alumina nanoscaffold (HAN) thus acting as a robust nanostructural platform for assembling the active material for MSCs.

\section{MATERIALS FOR MICRO-SUPERCAPACITORS}

Materials for MSCs includes oxide, MXene, graphene, etc. Recently, novel materials are transition metal silicide, boron carbide $\left(\mathrm{B}_{4} \mathrm{C}\right)$, and black phosphorus $(\mathrm{BP})$, Figure 5 shows the development timeline of micro-supercapacitor within 3 years.

\section{Transition Metal Silicide}

Transition metal silicide is a type of intermetallic compound formed by non-metallic silicon atoms entering the crystal lattice of the transition metal. When Si atoms are inserted into the lattice of the transition metal, the d-electron bonding strength of the atoms becomes weaker, and the coupling between the energy state of $\mathrm{Si}$ and the metal orbital makes the electronic structure and geometric structure of the metal silicide diversified, thus having different due to the special physical and chemical properties of metals, such as high melting point, low resistivity, good heat transfer and excellent high temperature resistance, oxidation resistance, and corrosion resistance, it has been widely used in electric heating elements, integrated circuits and high temperature anti-oxidation coating and other fields. In addition, the transition metal silicides possess excellent interface properties with silicon and obtain low internal resistance because they are binder-free electrode materials (Ramly et al., 2018). It is worth noting that in addition to the above advantages, transition metal silicides also show intentional electrochemical properties, such as high theoretical energy 


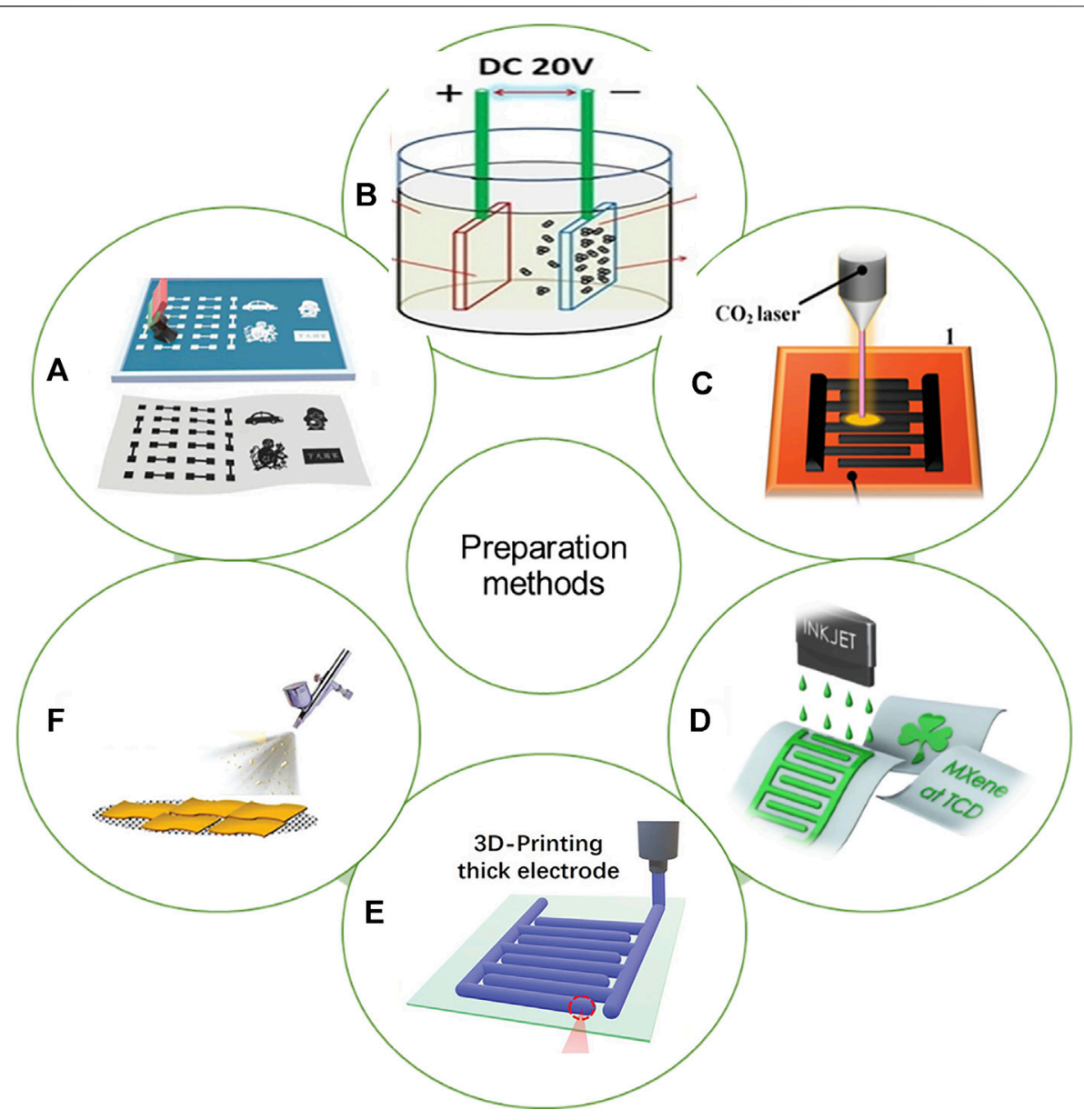

FIGURE 6 | Schematic of the fabrication MSCs via different methods, (A) screen printing (Liang et al., 2020), (B) electrodeposition (Li et al., 2017a), (C) laser processing (Wang et al., 2020b), (D) ink printing (Zhang et al., 2019) (E) 3D printing (Li et al., 2020)and (F) spray-masking (Zhao et al., 2019).

capacity and low discharge potential. Up to now, Transition metal silicides are prepared by various methods such as arc melting, self-propagating high temperature synthesis, mechanical alloying (MA) (Okadome et al., 1995; Al-Joubori and Suryanarayana, 2016; Shin et al., 2017), Solid-state metathesis (Jacubinas and Kaner, 1993; Nartowski and Parkin, 2002), Molten salt reaction technology (Ma et al., 2004; Yang et al., 2004; Liu et al., 2013; Estruga et al., 2014), Microwave assisted synthesis (Vaidhyanathan and Rao, 1997; Zhang et al., 2014; Zhang et al., 2018), Chemical vapour deposition (CVD) (Seo et al., 2007; In et al., 2008; Higgins et al., 2010; Liu et al., 2012) and Solution synthesis route (Baudouin et al., 2012; Geaney et al., 2012; Galeandro-Diamant et al., 2019) (Figure 6). Each method described above has its own advantages and disadvantages. With the development of nanotechnology, methods such as CVD, solution synthesis routes, and polymer-derived pyrolysis have replaced traditional high-temperature methods. These methods can be used to produce high surface area materials. And control the size of the metal silicide particles to ensure the low cost, repeatability, high yield and scalability of the production technology.

\section{Boron Carbide $\left(\mathrm{B}_{4} \mathrm{C}\right)$}

Boron carbide $\left(\mathrm{B}_{4} \mathrm{C}\right)$, also known as black diamond, is the third hardest material known in nature with a hardness ranking only second to diamond and cubic boron nitride. Compared with other materials, $\mathrm{B}_{4} \mathrm{C}$ has very remarkable physical and chemical properties, such as extremely high hardness (27.4-37.7 GPa), lightweight (low density $2.5 \mathrm{~g} \mathrm{~cm}^{-3}$ ), high melting point (over $2,400^{\circ} \mathrm{C}$ ), excellent corrosion resistance, high thermal stability, high elastic mode $(460 \mathrm{GPa})$ and high neutron absorption cross section (Song et al., 2019). Recently, $\mathrm{B}_{4} \mathrm{C}$ nanowires, one kind of P-type semiconductor with a good ductility (No cracking within $70^{\circ}$ bending angle) have become as one of the most promising candidates for electrode material. Compared with other 2D materials, few-layer BP always has a direct band gap, which can be adjusted between 0.30 and $2.2 \mathrm{eV}$ by controlling the number of layers (Hao et al., 2016). $\mathrm{B}_{4} \mathrm{C}$ has been prepared by various methods, such as vacuum heating synthesis strategy (Chang et al., 2020), spark plasma sintering (SPS) (Xu et al., 2012; Moshtaghioun et al., 2013; Sahani et al., 2016). The two preparation processes are simple, short cycle, good repeatability, low cost, and conducive to large-scale production. 


\section{Black Phosphorus (BP)}

As an emerging two-dimensional material, black phosphorus (BP) have been proven to be an excellent electrode material for supercapacitor due to large spacing $(5.3 \AA)$ and weak van der Waals interactions between adjacent puckered layers (Dong et al., 2016), adjustable band structure (Zhu et al., 2020a) and high electrical conductivity (300 S m$~^{-1}$ ) (Yang et al., 2021a), good mechanical properties (166 GPa) (Jiang and Park, 2014). These characteristics enable BP to obtain ideal electrochemical performance. Compared with other two-dimensional materials, BP has adjustable band gap, high carrier mobility and optical and electronic anisotropy, which is widely used in transistors, photoelectronics and electrochemical energy storage devices (Kou et al., 2015; Ling et al., 2015; Liu et al., 2015). Atomically thick BP layers can be prepared via mechanical exfoliation (Chen et al., 2015d; Zhang et al., 2015), plasma etching (Jia et al., 2015), liquid-phase exfoliation (Yasaei et al., 2015; Bat-Erdene et al., 2017), electrochemical exfoliation (Erande et al., 2016), microwave-assisted, sheer exfoliation, CVD (Smith et al., 2016), mineralizer-assisted gas-phase transformation method (Xu et al., 2016) and wet chemistry method (Son et al., 2011; Du et al., 2012; Yoo et al., 2014). Mechanical exfoliation and plasma etching methods has many disadvantages, including poor repeatability, and low production yield. The electrochemical exfoliation method can only be carried out through experiments, and it has not been practically applied. Liquid-phase exfoliation, microwave-assisted, sheer exfoliation, CVD, mineralizer-assisted gas-phase transformation method and wet chemistry method can produce $2 \mathrm{D}$ nanomaterials with high efficiency, low cost, high yield, simple and large-scale production (Qiu et al., 2017).

The conventional MSCs are elongated stage adopted sandwich configuration structures with dimensions typically ranging from twenty to thirty of micrometers in thickness, and a length of several millimeters to meters. the stacked structure is prone to short-circuit phenomenon. The two electrodes must be kept at a proper distance to avoid shortcircuiting of the device. At the same time, the electrode must load as much active material as possible to improve the energy storage capacity of the devices. At the same time, the electrode should be loaded with as many active materials as possible to improve the energy storage capacity of the device, both of which will increase the ion transport impedance and lead to a low power density; on the other hand, the sandwich laminated structure is too large to be integrated on microelectronic devices. Compared with the traditional sandwich structure supercapacitor, the planar micro supercapacitor is composed of cross-finger electrode. The gap between the two narrow forks is filled with electrolyte, which is conducive to the rapid transmission of electrolyte ions, thus achieving ultra-high power density. Thanks to the structure of the planar cross finger, the micro ultracapacitors not only maintain the ultralong cycle stability, but also show better performance than the traditional sandwich ultracapacitors. Up to now, in-plane interdigital MSCs with excellent electrochemical performance are prepared by various methods such as photolithography (Kim et al., 2013; Wu et al., 2014; Diao et al., 2020), ink printing (Li et al., 2017b; Zhang et al., 2019), screen-pritting (Li et al., 2019a; Abdolhosseinzadeh et al., 2020; Liang et al., 2020), laser processing (Xie et al., 2016; Tao et al., 2019; Wang et al., 2020b), spray-masking (Wang et al., 2017; Xiong et al., 2019; Zhao et al., 2019), electrodeposition (Makino et al., 2013; Li et al., 2017a; Asbani et al., 2021) and 3D printing (Yu et al., 2017; Yu et al., 2018; Wang et al., 2020c). Each method of MSCs preparation has its own advantages and disadvantages, and most of the methods are difficult to satisfy the preparation of multiple MSCs simultaneously. Therefore, the selection of preparation method needs to consider many factors such as the type of electrode material. Finally, the thickness of the electrode materials prepared by these preparation methods is summarized in Table 1. It is satisfactory that the thickness of the materials prepared by all the preparation methods has reached the nanometer level.

\section{APPLICATION OF MICRO-SUPERCAPACITORS}

MSCs have the potential of world market compared to other energy storage devices in various applications due to their superior performance with higher power density, fast rates of charge and discharge, and longer operating lifetime. MSCs are commonly applied in aerospace and automotive application, portable electronic devices, rollable displays, miniature biomedical equipment and other systems. We mainly introduce the application in medical diagnosis and industrial in recent years.

\section{Implanted Parts in the Body in Health Monitoring}

In order to realize real-time health monitoring and accurate diagnosis and treatment, implantable medical electronic devices such as Pacemaker and Neurostimulator and other sensor systems have made rapid progress. In terms of the powering capability, implantable MSCs are generally in pursuit of high energy/power density, a fast charge-discharge rate and large mechanically deformable, thus biocompatible material design is a key component. Recently, Kim and co-workers (Sim et al., 2018) reported a promising electrode material with a high flexibility and excellent electrochemical behavior. By trapping poly (3,4-ethylenedioxythiophene): poly (styrenesulfonate) and ferritin on multiwalled carbon nanotube, the fiber electrodes exhibited electrochemical stability and the electrical conductivity. Based on this, the capacitance loss of $16 \%$ in the mouse after 8 days, and fiber electrodes achieved excellent performance for validated biocompatibility for In vivo phenomena and cell response tests. In contrast to conventional battery/capacitor couple, a single material with the mixed electrochemical behavior for one device is of great improvement for the powering function within limited space.

Power biodegradable and implantable MSCs have attracted numerous investigations due to the needs for smart implantable 
TABLE 1 | Thickness of electrode materials via different preparation methods.

\begin{tabular}{|c|c|c|c|}
\hline Method & Materials & Min thickness & References \\
\hline Photolithography & MXene & $300 \mathrm{~nm}$ & Couly et al. (2018) \\
\hline- & MXene/CNT & 30 nm & Kim et al. (2021) \\
\hline- & $\mathrm{OAm} @ \mathrm{Ti}_{3} \mathrm{C}_{2} \mathrm{Tx}$ & $600 \mathrm{~nm}$ & Song et al. (2020) \\
\hline Ink printing & Porous graphene microspheres & $30 \mu \mathrm{m}$ & Chang et al. (2021) \\
\hline- & Graphene & $30 \mathrm{~nm}$ & Sollami Delekta et al. (2019) \\
\hline 3D Printing & MXene & $1.5 \mu \mathrm{m}$ & Orangi et al. (2020) \\
\hline- & MXene-AgNW-MnONW-C60 & $500 \mu \mathrm{m}$ & Li et al. (2020) \\
\hline- & Graphene-carbon black & $35 \mu \mathrm{m}$ & Zhang et al. (2021) \\
\hline Spray-masking & MXene & $20 \mathrm{~nm}$ & Li et al. (2019b) \\
\hline Electrochemical deposition & Polyethylenedioxythiophene & $600 \mathrm{~nm}$ & Kurra et al. (2015) \\
\hline Laser processing & Carbon nanotubes (CNTs)@polypyrrole (PPy) & $24.64 \mathrm{~nm}$ & Li et al. (2021) \\
\hline
\end{tabular}

(a)

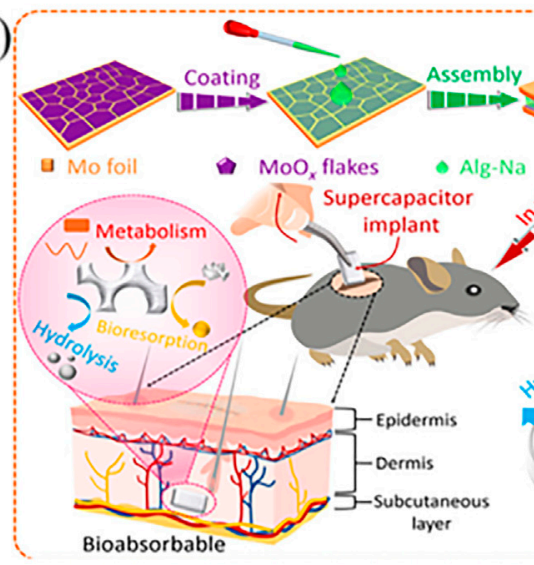

(d)

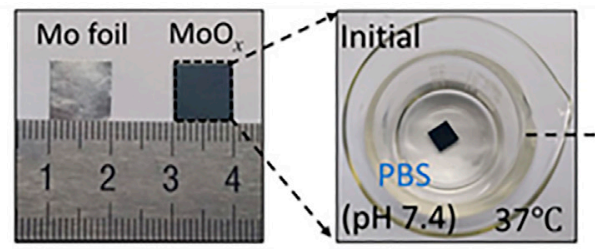

Packaging disappear

(e)

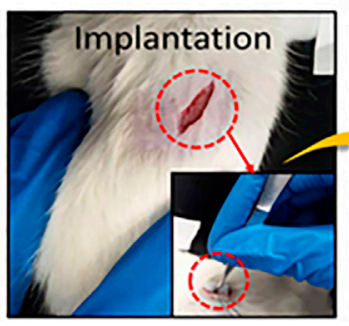

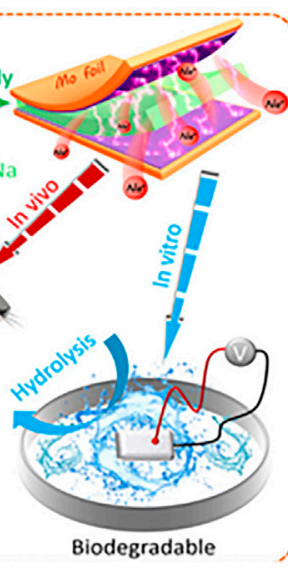
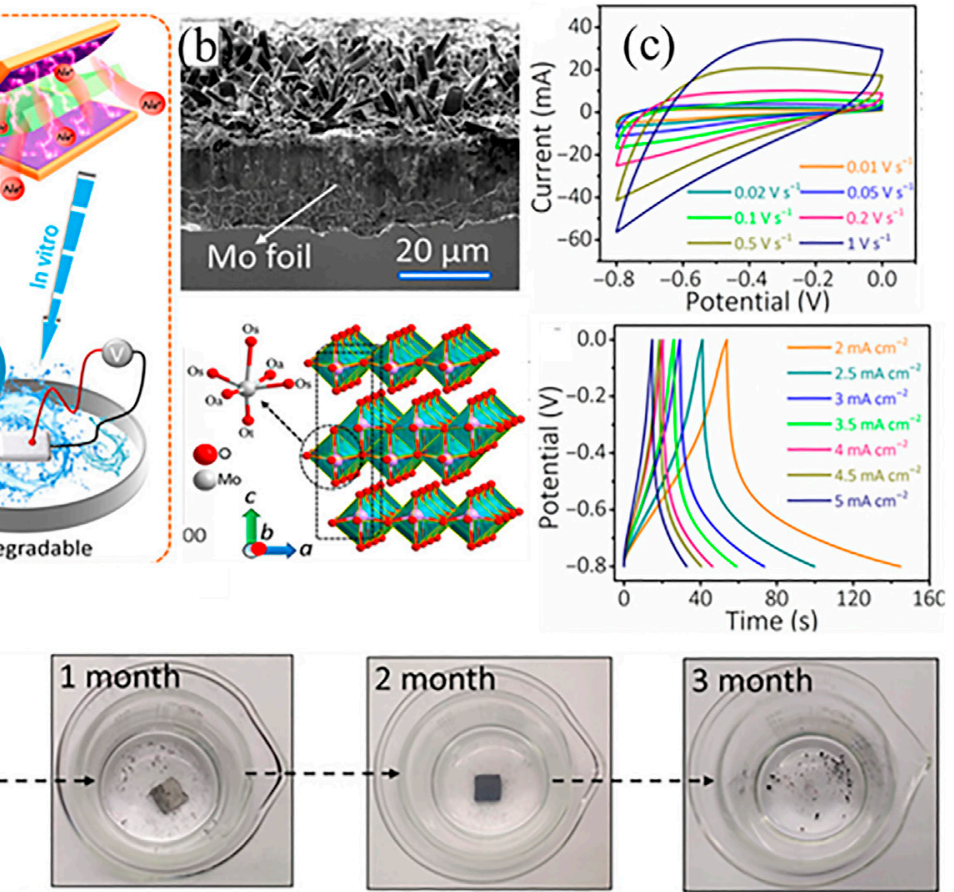

Residuals

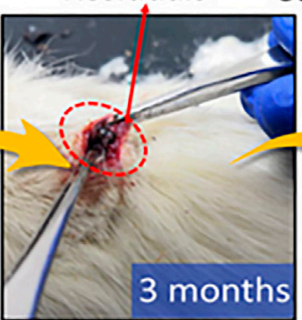

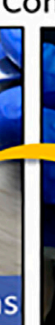

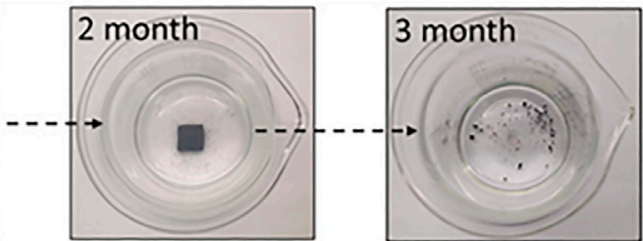

Complete degradation
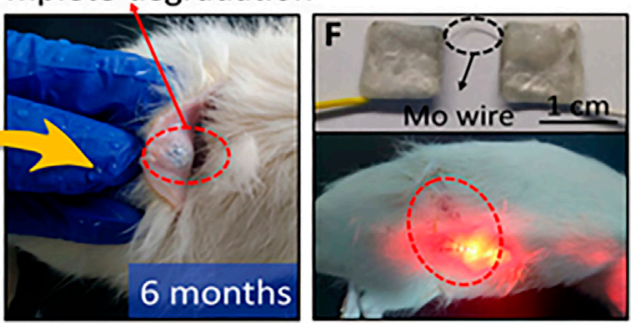

FIGURE 7 | (A) Schematic representations of the synthesis procedure and applications of the biodegradable MSCs. (B) SEM image and crystal structure of MoOx electrode. (C) CV and GCD curves of MoOx electrode. (D) Digital pictures of the time-sequential dissolution of a single MoOx electrode (1 $\mathrm{cm} \times 1 \mathrm{~cm})$ immersed in PBS $(\mathrm{pH} 7.4)$ at $37^{\circ} \mathrm{C}$. (E) In vivo degradation evaluation of the supercapacitor implant in the subcutaneous area of SD rats (Sheng et al., 2021).

medical electronics. Very recently, Sheng's group (Sheng et al., 2021) reported on the fabrication of MoOx flake on water-soluble Mo foil by an electrochemical oxidation approach. The asprepared MoOx-based supercapacitor delivers a high specific

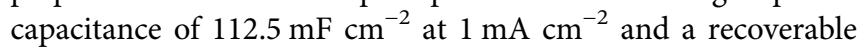

energy density of $15.64 \mathrm{Wh} \mathrm{cm}^{-2}$. The packaged device can work effectively for up to 1 month in a simulated body fluid environment $\left(37^{\circ} \mathrm{C}, 0.1 \mathrm{mM}\right.$ PBS solution, $\left.\mathrm{pH}=7.4\right)$, and the length of the working life is controllable, which is comparable to the other reported materials and suggests that it is indeed a 
promising energy storage device in terms of energy storage properties. In addition to electrochemical performance, $\mathrm{MoOx}$ flake have shown the biodegradation behaviors and biocompatibility. As shown in Figure 7D, Sheng's group further systematically studied its biodegradability by placing the MoOx electrode material in a neutral phosphate buffer filling solution. The study found that as time progressed, the $\mathrm{MoOx}$ flakes were first completely dissolved, and then the exposed Mo foil appeared to be cracked and corroded and decomposed into black powder. The above test is only a verification process, and the live implantation needs to be further proved its effectiveness. As shown in Figure 7E, 6 months after implanting the encapsulated biodegradable supercapacitor into a living mouse, the entire MSC device was completely dissolved, and the mouse did not show any inflammatory response. As we all know, molybdenum is an indispensable trace element to maintain the normal life activities of the human body, so the dissolution of electrode materials can also further provide the human body's daily demand for Mo element.

Apart from that, practical applications in the human body is also important for the practical MSC. Gao and co-workers developed biocompatible and edible MSC using a laser scribing strategy, which has a highly flexible and excellent electrochemical performance in bioenvironment. (Gao et al., 2020) Composed of gelatin, edible gold, active carbon (AC) and agar aqueous electrolyte, the flexible edible MSC could be charged to $2 \mathrm{~V}$ even after soaking in simulated gastric juice for $28 \mathrm{~min}$ and degrade completely in a simulated gastric fluid for $40 \mathrm{~min}$. Such flexible edible MSCs in a capsule was swallowed by testers, and the tester had no adverse reactions, which further proves the high safety of MSCs.

\section{External Fixation Components in Health Monitoring}

Yun and co-workers reported an integrated energy device for both generate photoelectric conversion, energy storage and sensing by fabricating MSC, strain sensor (SS) and commercial silicon-based solar cell (SC) on a single stretchable substrate. The MSC was obtained via photolithography and the e-beam evaporation. The integrated system would be charged when the MSC and SC were connected. The negative and positive charges generated from the DSSC part were transported toward the Ti wire and stored in the SC part shows the charging and discharging curves of the integrated optical charging system it was exposed to the light of the solar simulator. After being exposed to light, the voltage rapidly increased to $0.8 \mathrm{~V}$ within $2 \mathrm{~s}$. During the discharge process, it reached the open circuit voltage (Voc) of the MSC after about $1.2 \mathrm{~h}$. At the same time, in the mechanical stability test of the integrated system, after 1,000 cycles of repeated stretching (30\% biaxial stretching), the initial capacitance only dropped by $2 \%$, showing excellent electrochemical performance (Yun et al., 2018). Gong and co-workers used solution treatment series solar cells combining perovskite solar cells (PSCs) and ternar organic solar cells (OSCs), and then integrate PSCs-OSCs series solar cells with solid-state asymmetric ultracapactors through solution treatment conducting polymer film to build a wireless portable solution treatment self-charging power pack. Upon exposed to light, the power conversion efficiency and energy storage efficiency were calculated to be 17.16 and $72.4 \%$, respectively (Zhu et al., 2020b).

These integrated devices can efficiently collect solar energy. However, the solar energy has the disadvantages of random, intermittent and dispersive, and the use of solar energy is largely affected by the weather, working conditions, etc. As a result, cong (Cong et al., 2020) and co-workers recently developed a retractable coplanar self-charging system by integrating MSC prepared by chemical deposition and triboelectric nanogenerators into a common fabric, which can collect mechanical energy generated by human movement and converts it into electrical energy, resulting in a coplanar self-charging power textile (SCPT) as shown in Figure 8A. In this circuit, a bridge rectifier was used to charge the MSC with the current generated by the linear motor through beating of different frequencies. After 34 min of charging it to $2.0 \mathrm{~V}$ with a linear motor through a $4 \mathrm{~Hz}$ tapping, the self-chargeable power supply fabric can be used to power the electronic watch for $3 \mathrm{~min}$. Liu and co-workers (Liu et al., 2019c) recently developed a yarn-based electronic system for efficient energy harvesting, conversion and storage (Figure $\mathbf{8 B}$ ). To obtain the integrated energy textile, the negative electrode was first prepared by coating $\mathrm{Cu}$-coated polyester yarn with $\mathrm{rGO} / \mathrm{CNT}$, and the positive electrode was prepared by growing Ni-Co bimetallic oxyhydroxide on the polyester yarn. Both the energy harvesting part and the storage part exhibited good performances, as confirmed from the experimental results. The triboelectric nanogenerators part exhibited a peak areal

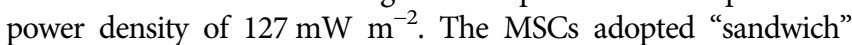
configuration and exhibited an areal energy density of $78.1 \mu \mathrm{Wh}$ $\mathrm{cm}^{-2}$. As a result, more complicated integrated system on an electronic textile is promising. $\mathrm{Li}$ and co-workers (Gao et al., 2021a) developed a $\mathrm{Ti}_{3} \mathrm{C}_{2} \mathrm{Tx}$-derived iontronic pressure sensor (TIPS). The sensor consists of a floating electrode on the top and a microstructure PVA-KOH dielectric film. $\mathrm{Ti}_{3} \mathrm{C}_{2} \mathrm{Tx}$ has excellent electronic conductivity $\left(\sim 10,000 \mathrm{~S} \mathrm{~cm} \mathrm{~cm}^{-1}\right)$, electrochemical, optical and mechanical properties, and has better pseudocapacitance characteristics based on ion intercalation than traditional electric double layer electrode materials. Selected as the electrode of flexible PPS. The floating electrode design and the microstructured dielectric film further enhance the sensitivity. Benefiting from the synergistic effect between the electrode material and the device configuration, TIPS exhibits unprecedented ultra-high sensitivity (Smin> $200 \mathrm{kPa}^{-1}, \quad$ Smax $\left.>\quad 45,000 \mathrm{kPa}^{-1}\right)$, wide sensing range $(20 \mathrm{~Pa}-1.4 \mathrm{MPa})$, and low the detection limit (LOD) is $20 \mathrm{~Pa}$ and has a stable long-term work durability of 10,000 cycles. These sensors can monitor physical activity and flexible robot tactile perception.

It is well known that body fluid is rich in chemicals such as different kinds of ions $(\mathrm{Na}, \mathrm{K}, \mathrm{Zn}, \mathrm{Fe})$, glucose and lactate. As non-invasive human body fluid monitoring provides health indicator information for human body, widespread research interest has been aroused by the related testing equipment. As far as sweat monitoring system is concerned, MCS for real-time health monitoring is generally in pursuit of high capacitance, biocompatible, flexible and long-term stability thus material design 
A

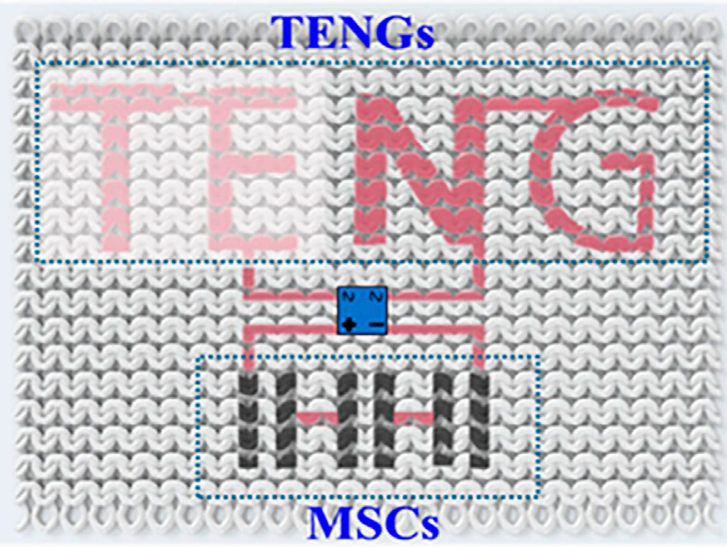

B

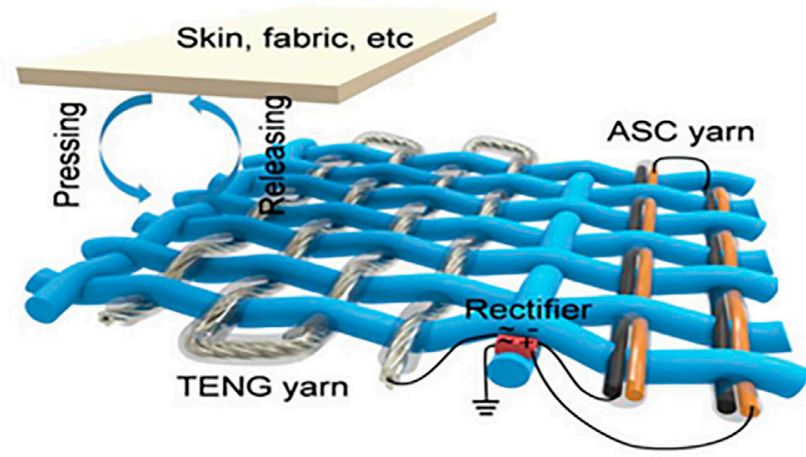

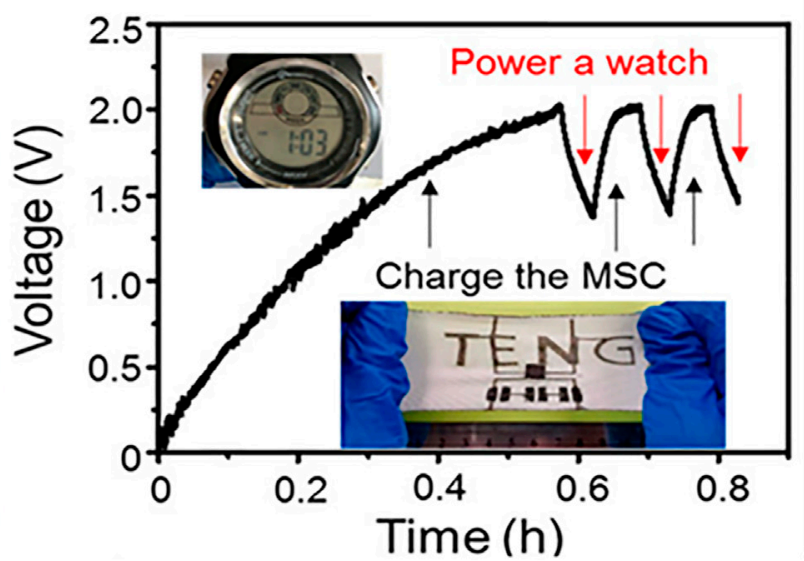
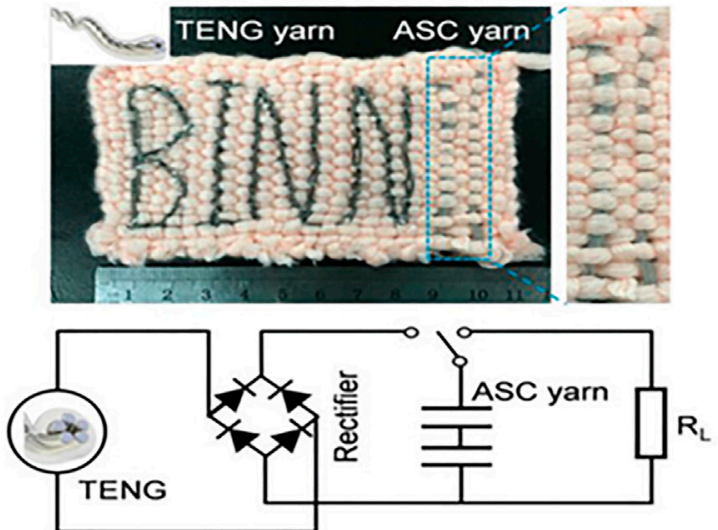

FIGURE 8 | (A) Schematic illustration of the coplanar self-charging power textile (Cong et al., 2020). (B) Schematic illustration, photograph and Equivalent circuit of the self-charging power textile (Liu et al., 2019c).
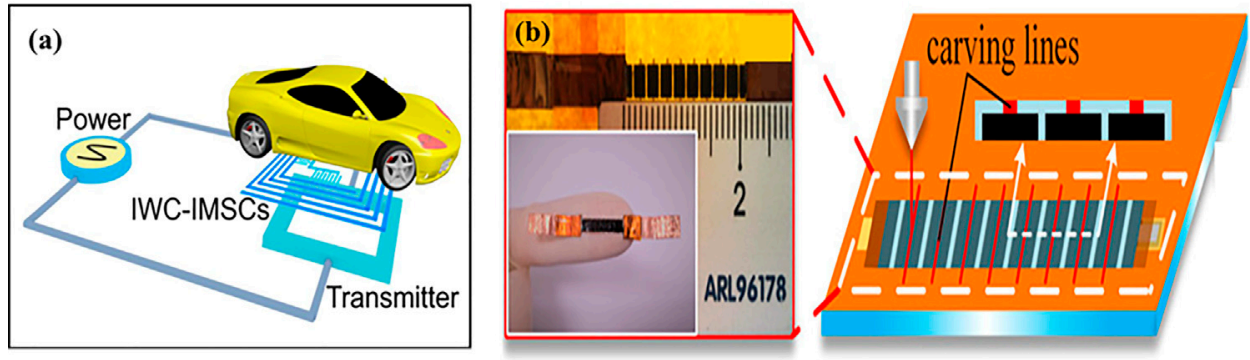

FIGURE 9 | (A) Schematic illustration of operation of pure electric bus by the wireless charging energy storage microdevices (Gao et al., 2021b). (B) Schematic illustration and photograph of the flexible high voltage MSCs (Bai et al., 2020).

with highly compacted smarting sensing system being the key part ( $\mathrm{Li}$ et al., 2019c; Lu et al., 2019). Recently, Lu and co-workers (Lu et al., 2019) developed a promising self-powered enzyme-free sensor arrays system with integrated flexible MSCs array. By coating the homogeneous mixed solution containing urchin-like $\mathrm{NiCo}_{2} \mathrm{O}_{4}$ and poly vinylidene fluoride on the lithographic $\mathrm{PET}$, the symmetric MSCs exhibited a high capacitance of $0.067 \mathrm{~F} \mathrm{~cm}^{-2}$ at $1.2 \mathrm{~mA} \mathrm{~cm}$ and a high energy density of $0.64 \mu \mathrm{Wh} \mathrm{cm} \mathrm{cm}^{-3}$ at $0.09 \mathrm{~mW} \mathrm{~cm} \mathrm{~cm}^{-3}$. Based on this, an excellent capacity retention of $96.6 \%$ was achieved for the MSCs after 20000 cycles. As-fabricated glucose sensor showed excellent response to glucose with concentrations ranging from 10 to $200 \mu \mathrm{M}$, and the detection limit of $10 \mu \mathrm{M}$ was estimated. For the sweat sensors, the response concentration ranges of $(\mathrm{Na})$ and $(\mathrm{K})$ were $10-80 \mathrm{mM}$ and $1-16 \mathrm{mM}$, respectively, indicating a high sensitivity to target solutions. As both the MSCs and the asfabricated sensor showed good performances, a self-powered 
TABLE 2 | The relevant information and the performance metrics of the produced MSCs.

\begin{tabular}{|c|c|c|c|c|c|c|}
\hline Active materials & $\begin{array}{l}\text { Operating } \\
\text { voltage }\end{array}$ & $\begin{array}{l}\text { Specific capacitance } \\
\qquad\left(\mathrm{F} \mathrm{g}^{-1}\right)\end{array}$ & Energy density & Power density & $\begin{array}{l}\text { Capacitance } \\
\text { retention }\end{array}$ & References \\
\hline $\begin{array}{l}\text { MXene-AgNW- } \\
\text { MnONW-C60 }\end{array}$ & $0-0.8 \mathrm{~V}$ & $\begin{array}{l}216.2 \mathrm{mF} \mathrm{cm}^{-2} \\
\left(10 \mathrm{mV} \mathrm{s}^{-1}\right)\end{array}$ & $19.2 \mu \mathrm{Wh} \mathrm{cm}^{-2}$ & $58.3 \mathrm{~mW} \mathrm{~cm}^{-2}$ & 85\% (10000 cycles) & Li et al. (2020) \\
\hline GP-AC & $0-3 \mathrm{~V}$ & $\begin{array}{c}63 \mathrm{mF} \mathrm{cm} \mathrm{cm}^{-2} \\
\left(0.5 \mathrm{~mA} \mathrm{~cm}^{-2}\right)\end{array}$ & $58.4 \mu \mathrm{Wh} \mathrm{cm}^{-2}$ & $0.57 \mathrm{~mW} \mathrm{~cm}^{-2}$ & 85\% (10000 cycles) & Gao et al. (2021b) \\
\hline Ni NPs & $0-3 \mathrm{~V}$ & $\begin{array}{l}20.4 \mathrm{mF} \mathrm{cm}^{-2} \\
\left(0.1 \mathrm{~mA} \mathrm{~cm}^{-2}\right)\end{array}$ & $25.4 \mu \mathrm{Wh} \mathrm{cm}^{-2}$ & $150 \mu \mathrm{W} \mathrm{cm}{ }^{-2}$ & 89\% (7,000 cycles) & Chae et al. (2021) \\
\hline $\begin{array}{l}\text { Laser irradiated } \\
\text { graphene }\end{array}$ & $0-1.2 \mathrm{~V}$ & $\begin{array}{c}2.32 \mathrm{mF} \mathrm{cm}^{-2} \\
\left(10 \mu \mathrm{A} \mathrm{cm}^{-2}\right)\end{array}$ & $0.46 \mathrm{mWh} \mathrm{cm}^{-2}$ & $0.57 \mathrm{~W} \mathrm{~cm}^{-2}$ & $\begin{array}{l}\sim 100 \% \text { (100000 } \\
\text { cycles) }\end{array}$ & $\begin{array}{l}\text { Kamboj et al. } \\
(2019)\end{array}$ \\
\hline Boron carbon Nitride & $0-1 \vee$ & $\begin{array}{c}72 \mathrm{mF} \mathrm{cm} \mathrm{cm}^{-2} \\
\left(0.15 \mathrm{~mA} \mathrm{~cm}^{-2}\right)\end{array}$ & $\begin{array}{l}10 \mathrm{~mW} \mathrm{~h} \mathrm{~cm}^{-2} \\
\left(0.15 \mathrm{~mA} \mathrm{~cm}^{-2}\right)\end{array}$ & $\begin{array}{l}487 \mathrm{~mW} \mathrm{~cm}^{-2} \\
\left(1 \mathrm{~mA} \mathrm{~cm}^{-2}\right)\end{array}$ & $\begin{array}{c}\sim 100 \% \text { ( } 800000 \\
\text { cycles) }\end{array}$ & $\begin{array}{l}\text { Karbhal et al. } \\
\text { (2021) }\end{array}$ \\
\hline MXene/SiC & $0-1.6 \mathrm{~V}$ & $\begin{array}{c}97.8 \mathrm{mF} \mathrm{cm}^{-2} \\
(1 \mathrm{~mA} \mathrm{~cm}-2)\end{array}$ & $8.69 \mu \mathrm{Wh} \mathrm{cm}^{-2}$ & $0.8 \mathrm{~mW} \mathrm{~cm}^{-2}$ & $90 \%$ (10000 cycles) & Xia et al. (2022) \\
\hline $\begin{array}{l}\text { Ox-SWCNT/PVA } \\
\mathrm{H}_{3} \mathrm{PO}_{4}\end{array}$ & $0-0.8 \mathrm{~V}$ & $\begin{array}{l}5-30 \mathrm{mF} \mathrm{cm}^{-2} \\
\left(0.1 \mathrm{~mA} \mathrm{~cm}^{-2}\right)\end{array}$ & $0.41 \mu \mathrm{Wh} \mathrm{cm}{ }^{-2}$ & $0.37 \mathrm{~mW} \mathrm{~cm}^{-2}$ & & Yang et al. (2021b) \\
\hline MnN oxide @MWCNT & $0-2 \vee$ & $\begin{array}{l}11.8 \mathrm{mF} \mathrm{cm} \\
\left(0.2 \mathrm{~mA} \mathrm{~cm}^{-2}\right)\end{array}$ & $6.58 \mu \mathrm{Wh} \mathrm{cm}^{-2}$ & $200 \mu \mathrm{W} \mathrm{cm}{ }^{-2}$ & $78 \%$ (5,000 cycles) & Park et al. (2021) \\
\hline MXene/BC@PPy & $0-1.9 \mathrm{~V}$ & $\begin{array}{l}388 \mathrm{mF} \mathrm{cm}-2 \\
\left(1 \mathrm{~mA} \mathrm{~cm}^{-2}\right)\end{array}$ & $145.4 \mu \mathrm{Wh} \mathrm{cm}{ }^{-2}$ & $0.36 \mathrm{~mW} \mathrm{~cm}^{-2}$ & $\begin{array}{c}95.8 \%(25000 \\
\text { cycles })\end{array}$ & Cheng et al. (2021) \\
\hline Pristine graphene & $0-1 \vee$ & $1.57 \mathrm{~F} \mathrm{~cm}^{-2}\left(2 \mathrm{~mA} \mathrm{~cm}^{-2}\right)$ & $51.2 \mu \mathrm{Wh} \mathrm{cm}^{-2}$ & $0.968 \mathrm{~mW} \mathrm{~cm}^{-2}$ & $87.6 \%(4,500$ cycles $)$ & $\begin{array}{l}\text { Tagliaferri et al. } \\
(2021)\end{array}$ \\
\hline
\end{tabular}

wearable monitoring system was designed to achieve sensitive and convenient body fluid monitoring, as exhibited in Figure 10B.

\section{Industrial Applications of Micro-Supercapacitors}

Various applications for MSCs have been reported in the previous literature and are brief reviewed in this here, including electric vehicle, micro-drones, micro-robots, railways and high-voltage power devices. Zhang et al. used the same material (graphite paper) to prepare the high-consistent material system with wireless coils and electrodes by laser etching approach. Due to the complete and unique circuit structure, the wireless charging system will operate at a high transferring power efficiency (52.8\%), which affects the efficiency of the wireless charging energy storage microdevices. The electrochemical performances of a single MSC obtained the excellent capacitance of $454.1 \mathrm{mF} \mathrm{cm}{ }^{-2}$, higher than that of commercial Li-ion thin film batteries state-of-the-art conventional planar MSCs, superior than that of commercial thin film battery. And further when carefully integrated with the integrated wireless charging devices and MSCs, a microdevice integrating energy storage could drive the normal operation of pure electric bus, as demonstrated in Figure 9A (Gao et al., 2021b). Bai et al. (Bai et al., 2020) used laser radiation method to fabricate the flexible high voltage MSC (HVMSC) with series structure. As shown in Figure 9B, the device consists of the polyimide (PI) films, $\mathrm{KOH}$ electrolyte solution and graphene. Interestingly, the electrolyte layer on the surface of the laser-induced graphene is divided into several independent areas by the engraving line. In this process, conductive carbon black is formed, and the voltage of the MSCs is significantly increased through the alternate connection of electron and ion channels. Pang and co-workers (Pang et al., 2020)reported the application of MSCs for the forest fire monitoring and detection system as a power supply device.
The author adopted a sliding friction electrification model, which consists of two elastically connected fixed and sliding sleeve layers. The breeze swayed the branches, and the tiny shaking caused by the branches can be effectively collected and converted into electrical energy by triboelectric nanogenerator, and stored in the integrated micro super capacitor to power the fire sensor. The relevant information and performance of MSCs produced in recent years are summarized in Table 2 for comparison.

\section{CONCLUSION AND PROSPECTS}

The research and preparation of MSCs are originated from the demand for miniaturized and integrated micro-energy storage system and evolve into multiple forms of applications. This review gives a comprehensive overview of the recent developments from electrode materials to application orientations. Integrated miniature SCs have made huge research progress in terms of size, flexibility, biocompatibility and degradability. Even though the application of integrated flexible MSCs in health monitoring and industrial applications has been successfully demonstrated, several challenges and problems have not been overcome.

1) The interference of monitoring environmental factors such as temperature, moderate and $\mathrm{pH}$ conditions on the health monitoring system needs to be resolved.

2) As an energy storage device, MSCs play an important role in ensuring the continuity and stability of work in the entire monitoring system. When designing devices, consider the use of miniature, flexible energy storage devices with larger capacitance, higher energy, wider working range, and longer service life.

3) The biocompatibility and degradability of implantable MSCs have been verified in small animal models, and the real human clinical trials are still generally verified. 
4) There are differences in the performance of the MSCs, and the inconsistency of the voltages at the SCs will occur during the series use. If the MSCs is overvoltage or overcharged, its service life will be greatly reduced, and it will even cause permanent damage to the MSCs and greater voltage deviation.

\section{AUTHOR CONTRIBUTIONS}

$\mathrm{XS}, \mathrm{KC}, \mathrm{FL}, \mathrm{CZ}$, and DX wrote the manuscript. KC and DX proposed the idea in discussions with FL and CZ.

\section{REFERENCES}

Abdolhosseinzadeh, S., Schneider, R., Verma, A., Heier, J., Nüesch, F., and Zhang, C. (2020). Turning Trash into Treasure: Additive Free MXene Sediment Inks for Screen-Printed Micro-Supercapacitors. Adv. Mater. 32, 2000716. doi:10.1002/adma.202000716

Al-Joubori, A. A., and Suryanarayana, C. (2016). Synthesis of Stable and Metastable Phases in the Ni Si System by Mechanical Alloying. Powder Techn. 302, 8-14. doi:10.1016/j.powtec.2016.08.033

Arbizzani, C., Mastragostino, M., and Meneghello, L. (1996). Polymer-based Redox Supercapacitors: A Comparative Study. Electrochim. Acta 41, 21-26. doi:10.1016/0013-4686(95)00289-q

Archana, S., Athika, M., and Elumalai, P. (2020). Supercapattery and Full-Cell Lithium-Ion Battery Performances of a [Ni(Schiff Base)]-Derived Ni/NiO/ nitrogen-Doped Carbon Heterostructure. New J. Chem. 44, 12452-12464. doi:10.1039/d0nj01602k

Asbani, B., Robert, K., Roussel, P., Brousse, T., and Lethien, C. (2021). Asymmetric Micro-supercapacitors Based on Electrodeposited Ruo2 and Sputtered VN Films. Energ. Storage Mater. 37, 207-214. doi:10.1016/j.ensm.2021.02.006

Bai, S., Tang, Y., Wu, Y., Liu, J., Liu, H., Yuan, W., et al. (2020). High Voltage Microsupercapacitors Fabricated and Assembled by Laser Carving. ACS Appl. Mater. Inter. 12, 45541-45548. doi:10.1021/acsami.0c11935

Balcı, Ö., Buldu, M., Ammar, A., Kiraz, K., Somer, M., and Erdem, E. (2021). Defect-induced B4C electrodes for high energy density supercapacitor devices. Sci. Rep. 11, 11627. doi:10.1038/s41598-021-90878-0

Bat-Erdene, M., Batmunkh, M., Shearer, C. J., Tawfik, S. A., Ford, M. J., Yu, L., et al. (2017). Efficient and Fast Synthesis of Few-Layer Black Phosphorus via Microwave-Assisted Liquid-phase Exfoliation. Small Methods 1, 1700260. doi:10.1002/smtd.201700260

Baudouin, D., Szeto, K. C., Laurent, P., De Mallmann, A., Fenet, B., Veyre, L., et al. (2012). Nickel-Silicide Colloid Prepared under Mild Conditions as a Versatile Ni Precursor for More Efficient CO2 Reforming of CH4 Catalysts. J. Am. Chem. Soc. 134, 20624-20627. doi:10.1021/ja3111797

Bi, Z., Kong, Q., Cao, Y., Sun, G., Su, F., Wei, X., et al. (2019). Biomass-derived Porous Carbon Materials with Different Dimensions for Supercapacitor Electrodes: a Review. J. Mater. Chem. A. 7, 16028-16045. doi:10.1039/ c9ta04436a

Boota, M., and Gogotsi, Y. (2019). MXene-Conducting Polymer Asymmetric Pseudocapacitors. Adv. Energ. Mater. 9, 1802917. doi:10.1002/aenm.201802917

Chae, C., Kim, Y.-B., Lee, S. S., Kim, T.-H., Jo, Y., Kim, H.-S., et al. (2021). All-3Dprinted Solid-State Microsupercapacitors. Energ. Storage Mater. 40, 1-9. doi:10.1016/j.ensm.2021.04.038

Chang, P., Matsumura, K., Zhang, J., Qi, J., Wang, C., Kinumoto, T., et al. (2018). 2D Porous Carbon Nanosheets Constructed Using Few-Layer Graphene Sheets by a "Medium-Up" Strategy for Ultrahigh Power-Output EDLCs. J. Mater. Chem. A. 6, 10331-10339. doi:10.1039/c8ta02308e

Chang, Y., Sun, X., Ma, M., Mu, C., Li, P., Li, L., et al. (2020). Application of Hard Ceramic Materials B4C in Energy Storage: Design B4C@C Core-Shell Nanoparticles as Electrodes for Flexible All-Solid-State Microsupercapacitors with Ultrahigh Cyclability. Nano Energy 75, 104947. doi:10.1016/j.nanoen.2020.104947

\section{FUNDING}

This work was supported by National Natural Science Foundation of China (51832007), Natural Science Foundation of Shandong Province (ZR2020ZD35), and the High-tech Innovation Fund, CAS (GQRC-19-21).

\section{ACKNOWLEDGMENTS}

KC also acknowledges Qilu Young Scholars Program of Shandong University.

Chang, Q., Cao, C., Qiao, H., Hu, Y., Xiao, G., Shi, W., et al. (2021). Ink Transfer for Printed Flexible Microsupercapacitors. Carbon 178, 285-293. doi:10.1016/ j.carbon.2021.02.072

Chatterjee, D. P., and Nandi, A. K. (2021). A Review on the Recent Advances in Hybrid Supercapacitors. J. Mater. Chem. A. 9, 15880-15918. doi:10.1039/d1ta02505h

Chen, K., and Xue, D. (2017). Colloidal Paradigm in Supercapattery Electrode Systems. Nanotechnology 29, 024003. doi:10.1088/1361-6528/aa9bfd

Chen, K., and Xue, D. (2018). Colloidal Supercapattery: Redox Ions in Electrode and Electrolyte. Chem. Rec. 18, 282-292. doi:10.1002/tcr.201700037

Chen, K., Song, S., Li, K., and Xue, D. (2013). Water-soluble Inorganic Salts with Ultrahigh Specific Capacitance: Crystallization Transformation Investigation of $\mathrm{CuCl} 2$ Electrodes. CrystEngComm 15, 10367-10373. doi:10.1039/ c3ce $41802 \mathrm{~b}$

Chen, K., Noh, Y. D., Patel, R. R., Huang, W., Ma, J., Li, K., et al. (2014). Microwave- or Conventional-Hydrothermal Synthesis of Co-based Materials for Electrochemical Energy Storage. Ceramics Int. 40, 8183-8188. doi:10.1016/ j.ceramint.2014.01.014

Chen, X., Chen, K., Wang, H., and Xue, D. (2014). Functionality of Fe(NO3)3 Salts as Both Positive and Negative Pseudocapacitor Electrodes in Alkaline Aqueous Electrolyte. Electrochim. Acta 147, 216-224. doi:10.1016/j.electacta.2014.08.132

Chen, X., Chen, K., Wang, H., Song, S., and Xue, D. (2014). Crystallization of Fe3+ in an Alkaline Aqueous Pseudocapacitor System. CrystEngComm 16, 6707-6715. doi:10.1039/c4ce00660g

Chen, K., Yang, Y., Li, K., Ma, Z., Zhou, Y., and Xue, D. (2014). CoCl2 Designed as Excellent Pseudocapacitor Electrode Materials. ACS Sustain. Chem. Eng. 2, 440-444. doi:10.1021/sc400338c

Chen, K., Xue, D., and Komarneni, S. (2015). Colloidal Pseudocapacitor: Nanoscale Aggregation of Mn Colloids from $\mathrm{MnCl} 2$ under Alkaline Condition. J. Power Sourc. 279, 365-371. doi:10.1016/j.jpowsour.2015.01.017

Chen, X., Chen, K., Wang, H., and Xue, D. (2015). A Colloidal Pseudocapacitor: Direct Use of Fe(NO3)3 in Electrode Can lead to a High Performance Alkaline Supercapacitor System. J. Colloid Interf. Sci. 444, 49-57. doi:10.1016/ j.jcis.2014.12.026

Chen, K., Yin, S., and Xue, D. (2015). A Binary AxB1-x Ionic Alkaline Pseudocapacitor System Involving Manganese, Iron, Cobalt, and Nickel: Formation of Electroactive Colloids via In Situ Electric Field Assisted Coprecipitation. Nanoscale 7, 1161-1166. doi:10.1039/c4nr05880a

Chen, Y., Jiang, G., Chen, S., Guo, Z., Yu, X., Zhao, C., et al. (2015). Mechanically Exfoliated Black Phosphorus as a New Saturable Absorber for Both Q-Switching and Mode-Locking Laser Operation. Opt. Express 23, 12823-12833. doi:10.1364/oe.23.012823

Chen, X., Paul, R., and Dai, L. (2017). Carbon-based Supercapacitors for Efficient Energy Storage. Natl. Sci. Rev. 4, 453-489. doi:10.1093/nsr/nwx009

Chen, K., Liang, F., and Xue, D. (2020). La3+:Ni-Cl Oxyhydroxide Gels with Enhanced Electroactivity as Positive Materials for Hybrid Supercapacitors. Dalton Trans. 49, 1107-1115. doi:10.1039/c9dt04410h

Cheng, W., Fu, J., Hu, H., and Ho, D. (2021). Interlayer Structure Engineering of MXene-Based Capacitor-Type Electrode for Hybrid Micro-Supercapacitor toward Battery-Level Energy Density. Adv. Sci. 8, 2100775. doi:10.1002/ advs.202100775

Choudhary, R. B., Ansari, S., and Majumder, M. (2021). Recent Advances on Redox Active Composites of Metal-Organic Framework and Conducting Polymers as 
Pseudocapacitor Electrode Material. Renew. Sustain. Energ. Rev. 145, 110854. doi:10.1016/j.rser.2021.110854

Cong, Z., Guo, W., Guo, Z., Chen, Y., Liu, M., Hou, T., et al. (2020). Stretchable Coplanar Self-Charging Power Textile with Resist-Dyeing Triboelectric Nanogenerators and Microsupercapacitors. ACS Nano 14, 5590-5599. doi:10.1021/acsnano.9b09994

Couly, C., Alhabeb, M., Van Aken, K. L., Kurra, N., Gomes, L., Navarro-Suárez, A. M., et al. (2018). Asymmetric Flexible MXene-Reduced Graphene Oxide MicroSupercapacitor. Adv. Electron. Mater. 4, 1700339. doi:10.1002/aelm.201700339

Diao, Y., Lu, Y., Yang, H., Wang, H., Chen, H., and D'Arcy, J. M. (2020). Direct Conversion of Fe $2 \mathrm{O} 3$ to 3D Nanofibrillar PEDOT Microsupercapacitors. Adv. Funct. Mater. 30, 2003394. doi:10.1002/adfm.202003394

Dong, S., Zhang, A., Liu, K., Ji, J., Ye, Y. G., Luo, X. G., et al. (2016). UltralowFrequency Collective Compression Mode and Strong Interlayer Coupling in Multilayer Black Phosphorus. Phys. Rev. Lett. 116, 087401. doi:10.1103/ PhysRevLett.116.087401

Du, Y., Yin, Z., Zhu, J., Huang, X., Wu, X.-J., Zeng, Z., et al. (2012). A General Method for the Large-Scale Synthesis of Uniform Ultrathin Metal Sulphide Nanocrystals. Nat. Commun. 3, 1177. doi:10.1038/ncomms2181

Erande, M. B., Pawar, M. S., and Late, D. J. (2016). Humidity Sensing and Photodetection Behavior of Electrochemically Exfoliated Atomically ThinLayered Black Phosphorus Nanosheets. ACS Appl. Mater. Inter. 8, 11548-11556. doi:10.1021/acsami.5b10247

Estruga, M., Girard, S. N., Ding, Q., Chen, L., Li, X., and Jin, S. (2014). Facile and Scalable Synthesis of Ti5Si3nanoparticles in Molten Salts for Metal-Matrix Nanocomposites. Chem. Commun. 50, 1454-1457. doi:10.1039/c3cc48168a

Fang, B., and Binder, L. (2006). A Modified Activated Carbon Aerogel for HighEnergy Storage in Electric Double Layer Capacitors. J. Power Sourc. 163, 616-622. doi:10.1016/j.jpowsour.2006.09.014

Galeandro-Diamant, T., Suleimanov, I., Veyre, L., Bousquié, M., Meille, V., and Thieuleux, C. (2019). Alkene Hydrosilylation with Supported and Unsupported $\mathrm{Ni}$ Nanoparticles: strong Influence of the $\mathrm{Ni}$ Environment on Activity and Selectivity. Catal. Sci. Technol. 9, 1555-1558. doi:10.1039/c8cy01487f

Gao, C., Bai, C., Gao, J., Xiao, Y., Han, Y., Shaista, A., et al. (2020). A Directly Swallowable and Ingestible Micro-supercapacitor. J. Mater. Chem. A. 8, 4055-4061. doi:10.1039/c9ta12880h

Gao, L., Wang, M., Wang, W., Xu, H., Wang, Y., Zhao, H., et al. (2021). Highly Sensitive Pseudocapacitive Iontronic Pressure Sensor with Broad Sensing Range. Nano-Micro Lett. 13, 140. doi:10.1007/s40820-021-00664-w

Gao, C., Huang, J., Xiao, Y., Zhang, G., Dai, C., Li, Z., et al. (2021). A Seamlessly Integrated Device of Micro-supercapacitor and Wireless Charging with Ultrahigh Energy Density and Capacitance. Nat. Commun. 12, 2647. doi:10.1038/s41467-021-22912-8

Geaney, H., Dickinson, C., O’Dwyer, C., Mullane, E., Singh, A., and Ryan, K. M. (2012). Growth of Crystalline Copper Silicide Nanowires in High Yield within a High Boiling Point Solvent System. Chem. Mater. 24, 4319-4325. doi:10.1021/ cm302066n

Guo, B., Yang, Y., Hu, Z., An, Y., Zhang, Q., Yang, X., et al. (2017). Redox-active Organic Molecules Functionalized Nitrogen-Doped Porous Carbon Derived from Metal-Organic Framework as Electrode Materials for Supercapacitor. Electrochim. Acta 223, 74-84. doi:10.1016/j.electacta.2016.12.012

Hao, C., Yang, B., Wen, F., Xiang, J., Li, L., Wang, W., et al. (2016). Flexible AllSolid-State Supercapacitors Based on Liquid-Exfoliated Black-Phosphorus Nanoflakes. Adv. Mater. 28, 3194-3201. doi:10.1002/adma.201505730

Higgins, J. M., Ding, R., DeGrave, J. P., and Jin, S. (2010). Signature of Helimagnetic Ordering in Single-Crystal MnSi Nanowires. Nano Lett. 10, 1605-1610. doi:10.1021/nl904042m

Hwang, S.-W., and Hyun, S.-H. (2007). Synthesis and Characterization of Tin Oxide/carbon Aerogel Composite Electrodes for Electrochemical Supercapacitors. J. Power Sourc. 172, 451-459. doi:10.1016/ j.jpowsour.2007.07.061

In, J., Varadwaj, K. S. K., Seo, K., Lee, S., Jo, Y., Jung, M.-H., et al. (2008). SingleCrystalline Ferromagnetic Fe1-xCoxSi Nanowires. J. Phys. Chem. C 112, 4748-4752. doi:10.1021/jp7105346,

Jacubinas, R. M., and Kaner, R. B. (1993). Synthesis of High-Temperature Silicides via Rapid Solid-State Metathesis. MRS Proc. 322, 133. doi:10.1557/proc$322-133$
Jia, J., Jang, S. K., Lai, S., Xu, J., Choi, Y. J., Park, J.-H., et al. (2015). PlasmaTreated Thickness-Controlled Two-Dimensional Black Phosphorus and its Electronic Transport Properties. ACS Nano 9, 8729-8736. doi:10.1021/ acsnano.5b04265

Jiang, Y., and Liu, J. (2019). Definitions of Pseudocapacitive Materials: A Brief Review. Energy Environ. Mater. 2, 30-37. doi:10.1002/eem2.12028

Jiang, J.-W., and Park, H. S. (2014). Mechanical Properties of Single-Layer Black Phosphorus. J. Phys. D: Appl. Phys. 47, 385304. doi:10.1088/0022-3727/47/38/ 385304

Jiang, H., Ma, J., and Li, C. (2012). Mesoporous Carbon Incorporated Metal Oxide Nanomaterials as Supercapacitor Electrodes. Adv. Mater. 24, 4197-4202. doi:10.1002/adma.201104942

Kamboj, N., Purkait, T., Das, M., Sarkar, S., Hazra, K. S., and Dey, R. S. (2019). Ultralong Cycle Life and Outstanding Capacitive Performance of a $10.8 \mathrm{~V}$ Metal Free Micro-supercapacitor with Highly Conducting and Robust LaserIrradiated Graphene for an Integrated Storage Device. Energy Environ. Sci. 12, 2507-2517. doi:10.1039/c9ee01458f

Karbhal, I., Basu, A., Patrike, A., and Shelke, M. V. (2021). Laser Patterning of boron Carbon Nitride Electrodes for Flexible Micro-supercapacitor with Remarkable Electrochemical Stability/capacity. Carbon 171, 750-757. doi:10.1016/j.carbon.2020.09.053

Kim, D., Shin, G., Kang, Y. J., Kim, W., and Ha, J. S. (2013). Fabrication of a Stretchable Solid-State Micro-supercapacitor Array. ACS Nano 7, 7975-7982. doi:10.1021/nn403068d

Kim, Y. H., Park, B. H., Choi, Y. J., Lee, G.-W., Kim, H.-K., and Kim, K.-B. (2020). Compact Graphene Powders with High Volumetric Capacitance: Microspherical Assembly of Graphene via Surface Modification Using Cyanamide. Energ. Storage Mater. 24, 351-361. doi:10.1016/j.ensm.2019.07.039

Kim, E., Lee, B.-J., Maleski, K., Chae, Y., Lee, Y., Gogotsi, Y., et al. (2021). Microsupercapacitor with a $500 \mathrm{Nm}$ gap between MXene/CNT Electrodes. Nano Energy 81, 105616. doi:10.1016/j.nanoen.2020.105616

Kou, L., Chen, C., and Smith, S. C. (2015). Phosphorene: Fabrication, Properties, and Applications. J. Phys. Chem. Lett. 6, 2794-2805. doi:10.1021/ acs.jpclett.5b01094

Kshetri, T., Thanh, T. D., Singh, S. B., Kim, N. H., and Lee, J. H. (2018), Hierarchical Material of Carbon Nanotubes Grown on Carbon Nanofibers for High Performance Electrochemical Capacitor. Chem. Eng. J. 345, 39-47. doi:10.1016/j.cej.2018.03.143

Kumar, U. N., Ghosh, S., and Thomas, T. (2019). Metal Oxynitrides as Promising Electrode Materials for Supercapacitor Applications. ChemElectroChem 6, 1255-1272. doi:10.1002/celc.201801542

Kumar, S., Saeed, G., Zhu, L., Hui, K. N., Kim, N. H., and Lee, J. H. (2021). 0D to 3D Carbon-Based Networks Combined with Pseudocapacitive Electrode Material for High Energy Density Supercapacitor: A Review. Chem. Eng. J. 403, 126352. doi:10.1016/j.cej.2020.126352

Kurra, N., Hota, M. K., and Alshareef, H. N. (2015). Conducting Polymer Microsupercapacitors for Flexible Energy Storage and Ac Line-Filtering. Nano Energy 13, 500-508. doi:10.1016/j.nanoen.2015.03.018

Lee, H. J., Lee, J. H., Chung, S.-Y., and Choi, J. W. (2016). Enhanced Pseudocapacitance in Multicomponent Transition-Metal Oxides by Local Distortion of Oxygen Octahedra. Angew. Chem. Int. Ed. 55, 3958-3962. doi:10.1002/anie.201511452

Lei, C., Amini, N., Markoulidis, F., Wilson, P., Tennison, S., and Lekakou, C. (2013). Activated Carbon from Phenolic Resin with Controlled Mesoporosity for an Electric Double-Layer Capacitor (EDLC). J. Mater. Chem. A. 1, 6037-6042. doi:10.1039/c3ta01638b

Lei, Z., Liu, L., Zhao, H., Liang, F., Chang, S., Li, L., et al. (2020). Nanoelectrode Design from Microminiaturized Honeycomb Monolith with Ultrathin and Stiff Nanoscaffold for High-Energy Micro-supercapacitors. Nat. Commun. 11, 299. doi:10.1038/s41467-019-14170-6

Li, Y.-Q., Shi, X.-M., Lang, X.-Y., Wen, Z., Li, J.-C., and Jiang, Q. (2016). Remarkable Improvements in Volumetric Energy and Power of 3D MnO2Microsupercapacitors by Tuning Crystallographic Structures. Adv. Funct. Mater. 26, 1830-1839. doi:10.1002/adfm.201504886

Li, L., Fu, C., Lou, Z., Chen, S., Han, W., Jiang, K., et al. (2017). Flexible Planar Concentric Circular Micro-supercapacitor Arrays for Wearable Gas Sensing Application. Nano Energy 41, 261-268. doi:10.1016/j.nanoen.2017.08.060 
Li, J., Sollami Delekta, S., Zhang, P., Yang, S., Lohe, M. R., Zhuang, X., et al. (2017). Scalable Fabrication and Integration of Graphene Microsupercapacitors through Full Inkjet Printing. ACS Nano 11, 8249-8256. doi:10.1021/acsnano.7b03354

Li, H., Liu, S., Li, X., Wu, Z.-S., and Liang, J. (2019). Screen-printing Fabrication of High Volumetric Energy Density Micro-supercapacitors Based on HighResolution Thixotropic-Ternary Hybrid Interdigital Micro-electrodes. Mater. Chem. Front. 3, 626-635. doi:10.1039/c8qm00639c

Li, J., Levitt, A., Kurra, N., Juan, K., Noriega, N., Xiao, X., et al. (2019). MXeneconducting Polymer Electrochromic Microsupercapacitors. Energ. Storage Mater. 20, 455-461. doi:10.1016/j.ensm.2019.04.028

Li, Y., Zheng, L., and Wang, X. (2019). Flexible and Wearable Healthcare Sensors for Visual Reality Health-Monitoring. Virtual Reality Intell. Hardware 1, 411-427. doi:10.1016/j.vrih.2019.08.001

Li, X., Li, H., Fan, X., Shi, X., and Liang, J. (2020). 3D-Printed Stretchable MicroSupercapacitor with Remarkable Areal Performance. Adv. Energ. Mater. 10, 1903794. doi:10.1002/aenm.201903794

Li, Z., Song, J., Hu, H., Yuan, C., Wu, M., and Ho, D. (2021). Rolled-up IslandBridge (RIB): a New and General Electrode Configuration Design for a WireShaped Stretchable Micro-supercapacitor Array. J. Mater. Chem. A. 9, 2899-2911. doi:10.1039/d0ta10171k

Liang, X., Chen, K., and Xue, D. (2018). A Flexible and Ultrahigh Energy Density Capacitor via Enhancing Surface/Interface of Carbon Cloth Supported Colloids. Adv. Energ. Mater. 8, 1703329. doi:10.1002/aenm.201703329

Liang, J., Tian, B., Li, S., Jiang, C., and Wu, W. (2020). All-Printed MnHCF-MnO X -Based High-Performance Flexible Supercapacitors. Adv. Energ. Mater. 10, 2000022. doi:10.1002/aenm.202000022

Liao, M. D., Peng, C., Hou, S. P., Chen, J., Zeng, X. G., Wang, H.-L., et al. (2020). Large-Scale Synthesis of Nitrogen-Doped Activated Carbon Fibers with High Specific Surface Area for High-Performance Supercapacitors. Energy Technol. 8, 1901477. doi:10.1002/ente.201901477

Ling, X., Wang, H., Huang, S., Xia, F., and Dresselhaus, M. S. (2015). The Renaissance of Black Phosphorus. Proc. Natl. Acad. Sci. USA 112, 4523-4530. doi:10.1073/pnas.1416581112

Liu, G., Lin, Y.-C., Liao, L., Liu, L., Chen, Y., Liu, Y., et al. (2012). Domain Wall Motion in Synthetic Co2Si Nanowires. Nano Lett. 12, 1972-1976. doi:10.1021/ nl204510p

Liu, X., Fechler, N., and Antonietti, M. (2013). Salt Melt Synthesis of Ceramics, Semiconductors and Carbon Nanostructures. Chem. Soc. Rev. 42, 8237-8265. doi:10.1039/c3cs60159e

Liu, H., Du, Y., Deng, Y., and Ye, P. D. (2015). Semiconducting Black Phosphorus: Synthesis, Transport Properties and Electronic Applications. Chem. Soc. Rev. 44, 2732-2743. doi:10.1039/c4cs00257a

Liu, K.-1., Jiao, M.-l., Chang, P.-p., Wang, C.-y., and Chen, M.-m. (2018). Pitch-based Porous Aerogel Composed of Carbon Onion Nanospheres for Electric Double Layer Capacitors. Carbon 137, 304-312. doi:10.1016/j.carbon.2018.05.038

Liu, L., Zhao, H., Wang, Y., Fang, Y., Xie, J., and Lei, Y. (2018). Evaluating the Role of Nanostructured Current Collectors in Energy Storage Capability of Supercapacitor Electrodes with Thick Electroactive Materials Layers. Adv. Funct. Mater. 28, 1705107. doi:10.1002/adfm.201705107

Liu, L., Zhao, H., and Lei, Y. (2019). Advances on Three-dimensional Electrodes for Micro-supercapacitors: A Mini-review. InfoMat 1, 74-84. doi:10.1002/inf2.12007

Liu, L., Zhao, H., and Lei, Y. (2019). Review on Nanoarchitectured Current Collectors for Pseudocapacitors. Small Methods 3, 1800341. doi:10.1002/ smtd.201800341

Liu, M., Cong, Z., Pu, X., Guo, W., Liu, T., Li, M., et al. (2019). High-Energy Asymmetric Supercapacitor Yarns for Self-Charging Power Textiles. Adv. Funct. Mater. 29, 1806298. doi:10.1002/adfm.201806298

Lochmann, S., Grothe, J., Eckhardt, K., Leistenschneider, D., Borchardt, L., and Kaskel, S. (2018). Nanoimprint Lithography of Nanoporous Carbon Materials for Micro-supercapacitor Architectures. Nanoscale 10, 10109-10115. doi:10.1039/c8nr01535j

Lu, X., Wang, C., Favier, F., and Pinna, N. (2017). Electrospun Nanomaterials for Supercapacitor Electrodes: Designed Architectures and Electrochemical Performance. Adv. Energ. Mater. 7, 1601301. doi:10.1002/aenm.201601301

Lu, Y., Jiang, K., Chen, D., and Shen, G. (2019). Wearable Sweat Monitoring System with Integrated Micro-supercapacitors. Nano Energy 58, 624-632. doi:10.1016/ j.nanoen.2019.01.084
Ma, J., Gu, Y., Shi, L., Chen, L., Yang, Z., and Qian, Y. (2004). Synthesis and thermal Stability of Nanocrystalline Chromium Disilicide. J. Alloys Compd. 376, 176-179. doi:10.1016/j.jallcom.2003.12.015

Makino, S., Yamauchi, Y., and Sugimoto, W. (2013). Synthesis of ElectroDeposited Ordered Mesoporous RuOx Using Lyotropic Liquid crystal and Application toward Micro-supercapacitors. J. Power Sourc. 227, 153-160. doi:10.1016/j.jpowsour.2012.11.032

Miller, E. E., Hua, Y., and Tezel, F. H. (2018). Materials for Energy Storage: Review of Electrode Materials and Methods of Increasing Capacitance for Supercapacitors. J. Energ. Storage 20, 30-40. doi:10.1016/j.est.2018.08.009

Mori, T., Iwamura, S., Ogino, I., and Mukai, S. R. (2019). Cost-effective Synthesis of Activated Carbons with High Surface Areas for Electrodes of Non-aqueous Electric Double Layer Capacitors. Separat. Purif. Techn. 214, 174-180. doi:10.1016/j.seppur.2018.04.022

Morimoto, T., Hiratsuka, K., Sanada, Y., and Kurihara, K. (1996). Electric DoubleLayer Capacitor Using Organic Electrolyte. J. Power Sourc. 60, 239-247. doi:10.1016/s0378-7753(96)80017-6

Moshtaghioun, B. M., Cumbrera-Hernández, F. L., Gómez-García, D., de Bernardi-Martín, S., Domínguez-Rodríguez, A., Monshi, A., et al. (2013). Effect of Spark Plasma Sintering Parameters on Microstructure and RoomTemperature Hardness and Toughness of fine-grained boron Carbide (B4C). J. Eur. Ceram. Soc. 33, 361-369. doi:10.1016/j.jeurceramsoc.2012.08.028

Nartowski, A. M., and Parkin, I. P. (2002). Solid State Metathesis Synthesis of Metal Silicides; Reactions of Calcium and Magnesium Silicide with Metal Oxides. Polyhedron 21, 187-191. doi:10.1016/s0277-5387(01)00974-3

Okadome, K., Unno, K., and Arakawa, T. (1995). The Synthesis of Amorphous $\mathrm{M}-\mathrm{Si}$ (M=transition Metal) alloy Powders by Mechanical Alloying. J. Mater. Sci. 30, 1807-1810. doi:10.1007/bf00351614

Orangi, J., Hamade, F., Davis, V. A., and Beidaghi, M. (2020). 3D Printing of Additive-free 2D Ti3C2Tx (MXene) Ink for Fabrication of Microsupercapacitors with Ultra-high Energy Densities. ACS Nano 14, 640-650. doi:10.1021/acsnano.9b07325

Pang, Y., Chen, S., An, J., Wang, K., Deng, Y., Benard, A., et al. (2020). Multilayered Cylindrical Triboelectric Nanogenerator to Harvest Kinetic Energy of Tree Branches for Monitoring Environment Condition and Forest Fire. Adv. Funct. Mater. 30, 2003598. doi:10.1002/adfm.202003598

Park, H., Song, C., Jin, S. W., Lee, H., Keum, K., Lee, Y. H., et al. (2021). High Performance Flexible Micro-supercapacitor for Powering a Vertically Integrated Skin-Attachable Strain Sensor on a Bio-Inspired Adhesive. Nano Energy 83, 105837. doi:10.1016/j.nanoen.2021.105837

Qiu, M., Sun, Z. T., Sang, D. K., Han, X. G., Zhang, H., and Niu, C. M. (2017). Current Progress in Black Phosphorus Materials and Their Applications in Electrochemical Energy Storage. Nanoscale 9, 13384-13403. doi:10.1039/ c7nr03318d

Ramly, M. M., Omar, F. S., Rohaizad, A., Aspanut, Z., Rahman, S. A., and Goh, B. T. (2018). Solid-phase Diffusion Controlled Growth of Nickel Silicide Nanowires for Supercapacitor Electrode. Appl. Surf. Sci. 456, 515-525. doi:10.1016/ j.apsusc.2018.06.140

Sahani, P., Karak, S. K., Mishra, B., Chakravarty, D., and Chaira, D. (2016). Effect of Al Addition on SiC-B 4 C Cermet Prepared by Pressureless Sintering and Spark Plasma Sintering Methods. Int. J. Refractory Met. Hard Mater. 57, 31-41. doi:10.1016/j.ijrmhm.2016.02.005

Salunkhe, R. R., Kaneti, Y. V., and Yamauchi, Y. (2017). Metal-Organic Framework-Derived Nanoporous Metal Oxides toward Supercapacitor Applications: Progress and Prospects. ACS Nano 11, 5293-5308. doi:10.1021/acsnano.7b02796

Seo, K., Varadwaj, K. S. K., Mohanty, P., Lee, S., Jo, Y., Jung, M.-H., et al. (2007). Magnetic Properties of Single-Crystalline CoSi Nanowires. Nano Lett. 7, 1240-1245. doi:10.1021/nl070113h

Seol, M.-L., Nam, I., Ribeiro, E. L., Segel, B., Lee, D., Palma, T., et al. (2020). AllPrinted In-Plane Supercapacitors by Sequential Additive Manufacturing Process. ACS Appl. Energ. Mater. 3, 4965-4973. doi:10.1021/acsaem.0c00510

Sha, M., Zhao, H., and Lei, Y. (2021). Updated Insights into 3D Architecture Electrodes for Micropower Sources. Adv. Mater. 33, 2103304. doi:10.1002/ adma.202103304

Shao, H., Wu, Y.-C., Lin, Z., Taberna, P.-L., and Simon, P. (2020). Nanoporous Carbon for Electrochemical Capacitive Energy Storage. Chem. Soc. Rev. 49, 3005-3039. doi:10.1039/d0cs00059k 
Shen, C., Wang, X., Li, S., Wang, J. g., Zhang, W., and Kang, F. (2013). A HighEnergy-Density Micro Supercapacitor of Asymmetric MnO2-Carbon Configuration by Using Micro-fabrication Technologies. J. Power Sourc. 234, 302-309. doi:10.1016/j.jpowsour.2012.10.101

Sheng, H., Zhou, J., Li, B., He, Y., and Yu, C. (2021). A Thin, Deformable, HighPerformance Supercapacitor Implant that Can Be Biodegraded and Bioabsorbed within an Animal Body. Sci. Adv. 7, eabe3097. doi:10.1126/ sciadv.abe3097

Shin, M.-S., Lee, T.-W., Park, J.-B., Lim, S.-H., and Lee, S.-M. (2017). Postannealing Effects on the Electrochemical Performance of a Si/TiSi2 Heteronanostructured Anode Material Prepared by Mechanical Alloying. J. Power Sourc. 344, 152-159. doi:10.1016/j.jpowsour.2017.01.128

Sim, H. J., Choi, C., Lee, D. Y., Kim, H., Yun, J.-H., Kim, J. M., et al. (2018). Biomolecule Based Fiber Supercapacitor for Implantable Device. Nano Energy 47, 385-392. doi:10.1016/j.nanoen.2018.03.011

Smith, J. B., Hagaman, D., and Ji, H.-F. (2016). Growth of 2D Black Phosphorus Film from Chemical Vapor Deposition. Nanotechnology 27, 215602. doi:10.1088/0957-4484/27/21/215602

Soam, A., Arya, N., Singh, A., and Dusane, R. (2017). Fabrication of Silicon Nanowires Based On-Chip Micro-supercapacitor. Chem. Phys. Lett. 678, 46-50. doi:10.1016/j.cplett.2017.04.019

Sollami Delekta, S., Adolfsson, K. H., Benyahia Erdal, N., Hakkarainen, M., Östling, M., and Li, J. (2019). Fully Inkjet Printed Ultrathin Microsupercapacitors Based on Graphene Electrodes and a Nano-Graphene Oxide Electrolyte. Nanoscale 11, 10172-10177. doi:10.1039/c9nr01427f

Son, J. S., Yu, J. H., Kwon, S. G., Lee, J., Joo, J., and Hyeon, T. (2011). Colloidal Synthesis of Ultrathin Two-Dimensional Semiconductor Nanocrystals. Adv. Mater. 23, 3214-3219. doi:10.1002/adma.201101334

Song, N., Gao, Z., Zhang, Y., and Li, X. (2019). B4C Nanoskeleton Enabled, Flexible Lithium-Sulfur Batteries. Nano Energy 58, 30-39. doi:10.1016/ j.nanoen.2019.01.018

Song, T. E., Yun, H., Kim, Y. J., Jeon, H. S., Ha, K., Jung, H. T., et al. (2020). Vertically Aligned Nanopatterns of Amine-Functionalized Ti 3 C 2 MXene via Soft Lithography. Adv. Mater. Inter. 7, 2000424. doi:10.1002/admi.202000424

Tagliaferri, S., Nagaraju, G., Panagiotopoulos, A., Och, M., Cheng, G., Iacoviello, F., et al. (2021). Aqueous Inks of Pristine Graphene for 3D Printed Microsupercapacitors with High Capacitance. ACS Nano 15, 15342-15353. doi:10.1021/acsnano.1c06535

Tao, Y., Wei, C., Liu, J., Deng, C., Cai, S., and Xiong, W. (2019). Nanostructured Electrically Conductive Hydrogels Obtained via Ultrafast Laser Processing and Self-Assembly. Nanoscale 11, 9176-9184. doi:10.1039/c9nr01230c

Vaidhyanathan, B., and Rao, K. J. (1997). Microwave Assisted Synthesis of Technologically Important Transition Metal Silicides. J. Mater. Res. 12, 3225-3229. doi:10.1557/jmr.1997.0422

Wang, J., Tang, J., Xu, Y., Ding, B., Chang, Z., Wang, Y., et al. (2016). Interface Miscibility Induced Double-Capillary Carbon Nanofibers for Flexible Electric Double Layer Capacitors. Nano Energy 28, 232-240. doi:10.1016/ j.nanoen.2016.08.043

Wang, X., Lu, Q., Chen, C., Han, M., Wang, Q., Li, H., et al. (2017). A Consecutive Spray Printing Strategy to Construct and Integrate Diverse Supercapacitors on Various Substrates. ACS Appl. Mater. Inter. 9, 28612-28619. doi:10.1021/ acsami.7b08833

Wang, L., Xie, X., Dinh, K. N., Yan, Q., and Ma, J. (2019). Synthesis, Characterizations, and Utilization of Oxygen-Deficient Metal Oxides for Lithium/sodium-Ion Batteries and Supercapacitors. Coord. Chem. Rev. 397, 138-167. doi:10.1016/j.ccr.2019.06.015

Wang, D.-G., Liang, Z., Gao, S., Qu, C., and Zou, R. (2020). Metal-organic Framework-Based Materials for Hybrid Supercapacitor Application. Coord. Chem. Rev. 404, 213093. doi:10.1016/j.ccr.2019.213093

Wang, W., Lu, L., Xie, Y., Yuan, W., Wan, Z., Tang, Y., et al. (2020). A Highly Stretchable Microsupercapacitor Using Laser-Induced Graphene/NiO/Co $3 \mathrm{O} 4$ Electrodes on a Biodegradable Waterborne Polyurethane Substrate. Adv. Mater. Technol. 5, 1900903. doi:10.1002/admt.201900903

Wang, Y., Zhang, Y., Liu, J., Wang, G., Pu, F., Ganesh, A., et al. (2020). Boosting Areal Energy Density of 3D Printed All-Solid-State Flexible Microsupercapacitors via Tailoring Graphene Composition. Energ. Storage Mater. 30, 412-419. doi:10.1016/j.ensm.2020.05.034
Wang, Y., Zhang, L., Hou, H., Xu, W., Duan, G., He, S., et al. (2021). Recent Progress in Carbon-Based Materials for Supercapacitor Electrodes: a Review. J. Mater. Sci. 56, 173-200. doi:10.1007/s10853-020-05157-6

Wei, L., and Yushin, G. (2012). Nanostructured Activated Carbons from Natural Precursors for Electrical Double Layer Capacitors. Nano Energy 1, 552-565. doi:10.1016/j.nanoen.2012.05.002

Wei, L., Sevilla, M., Fuertes, A. B., Mokaya, R., and Yushin, G. (2012). PolypyrroleDerived Activated Carbons for High-Performance Electrical Double-Layer Capacitors with Ionic Liquid Electrolyte. Adv. Funct. Mater. 22, 827-834. doi:10.1002/adfm.201101866

Witomska, S., Liu, Z., Czepa, W., Aliprandi, A., Pakulski, D., Pawluć, P., et al. (2019). Graphene Oxide Hybrid with Sulfur-Nitrogen Polymer for HighPerformance Pseudocapacitors. J. Am. Chem. Soc. 141, 482-487. doi:10.1021/jacs.8b11181

Wong, S. I., Lin, H., Sunarso, J., Wong, B. T., and Jia, B. (2020). Optimization of Ionic-Liquid Based Electrolyte Concentration for High-Energy Density Graphene Supercapacitors. Appl. Mater. Today 18, 100522. doi:10.1016/ j.apmt.2019.100522

Wu, Z.-S., Parvez, K., Feng, X., and Müllen, K. (2014). Photolithographic Fabrication of High-Performance All-Solid-State Graphene-Based Planar Micro-supercapacitors with Different Interdigital Fingers. J. Mater. Chem. A. 2, 8288-8293. doi:10.1039/c4ta00958d

Xia, M., Ning, J., Feng, X., Guo, H., Wang, D., Zhang, J., et al. (2022). Ionizationbombardment Assisted Deposition of MXene/SiC Heterostructure for Microsupercapacitor with Enhanced Sodium Storage. Chem. Eng. J. 428, 131114. doi:10.1016/j.cej.2021.131114

Xie, B., Wang, Y., Lai, W., Lin, W., Lin, Z., Zhang, Z., et al. (2016). Laser-processed Graphene Based Micro-supercapacitors for Ultrathin, Rollable, Compact and Designable Energy Storage Components. Nano Energy 26, 276-285. doi:10.1016/j.nanoen.2016.04.045

Xing, Z., Wang, B., Halsted, J. K., Subashchandrabose, R., Stickle, W. F., and Ji, X. (2015). Direct Fabrication of Nanoporous Graphene from Graphene Oxide by Adding a Gasification Agent to a Magnesiothermic Reaction. Chem. Commun. 51, 1969-1971. doi:10.1039/c4cc08977d

Xing, Z., Lu, J., and Ji, X. (2018). A Brief Review of Metallothermic Reduction Reactions for Materials Preparation. Small Methods 2, 1800062. doi:10.1002/ smtd.201800062

Xiong, Z., Yun, X., Qiu, L., Sun, Y., Tang, B., He, Z., et al. (2019). A Dynamic Graphene Oxide Network Enables Spray Printing of Colloidal Gels for HighPerformance Micro-Supercapacitors. Adv. Mater. 31, 1804434. doi:10.1002/ adma.201804434

Xu, C., Cai, Y., Flodström, K., Li, Z., Esmaeilzadeh, S., and Zhang, G.-J. (2012). Spark Plasma Sintering of B4C Ceramics: The Effects of Milling Medium and TiB2 Addition. Int. J. Refractory Met. Hard Mater. 30, 139-144. doi:10.1016/ j.ijrmhm.2011.07.016

Xu, Y., Yuan, J., Fei, L., Wang, X., Bao, Q., Wang, Y., et al. (2016). Selenium-Doped Black Phosphorus for High-Responsivity 2D Photodetectors. Small 12, 5000-5007. doi:10.1002/smll.201600692

Yang, Z., Gu, Y., Chen, L., Shi, L., Ma, J., and Qian, Y. (2004). Preparation of Mn5Si3 Nanocages and Nanotubes by Molten Salt Flux. Solid State. Commun. 130, 347-351. doi:10.1016/j.ssc.2004.02.008

Yang, J., Pan, Z., Zhong, J., Li, S., Wang, J., and Chen, P.-Y. (2021). Electrostatic Self-Assembly of Heterostructured Black PhosphorusMXene Nanocomposites for Flexible Microsupercapacitors with High Rate Performance. Energ. Storage Mater. 36, 257-264. doi:10.1016/ j.ensm.2020.12.025

Yang, H. J., Lee, J.-W., Seo, S. H., Jeong, B., Lee, B., Do, W. J., et al. (2021). Fully Stretchable Self-Charging Power Unit with Micro-supercapacitor and Triboelectric Nanogenerator Based on Oxidized Single-Walled Carbon Nanotube/polymer Electrodes. Nano Energy 86, 106083. doi:10.1016/ j.nanoen.2021.106083

Yasaei, P., Kumar, B., Foroozan, T., Wang, C., Asadi, M., Tuschel, D., et al. (2015). High-Quality Black Phosphorus Atomic Layers by Liquid-phase Exfoliation. Adv. Mater. 27, 1887-1892. doi:10.1002/adma.201405150

Yoo, D., Kim, M., Jeong, S., Han, J., and Cheon, J. (2014). Chemical Synthetic Strategy for Single-Layer Transition-Metal Chalcogenides. J. Am. Chem. Soc. 136, 14670-14673. doi:10.1021/ja5079943 
Yu, L., and Chen, G. Z. (2020). Supercapatteries as High-Performance Electrochemical Energy Storage Devices. Electrochem. Energ. Rev. 3, 271-285. doi:10.1007/s41918-020-00063-6

Yu, W., Zhou, H., Li, B. Q., and Ding, S. (2017). 3D Printing of Carbon NanotubesBased Microsupercapacitors. ACS Appl. Mater. Inter. 9, 4597-4604. doi:10.1021/acsami.6b13904

Yu, W., Li, B. Q., Ding, S., and Liu, H. (2018). 3D Printing of Interdigitated Electrode for All-Solid-State Microsupercapacitors. J. Micromech. Microeng. 28, 105014. doi:10.1088/1361-6439/aad107

Yun, J., Song, C., Lee, H., Park, H., Jeong, Y. R., Kim, J. W., et al. (2018). Stretchable Array of High-Performance Micro-supercapacitors Charged with Solar Cells for Wireless Powering of an Integrated Strain Sensor. Nano Energy 49, 644-654. doi:10.1016/j.nanoen.2018.05.017

Zhai, S., Karahan, H. E., Wang, C., Pei, Z., Wei, L., and Chen, Y. (2020). 1D Supercapacitors for Emerging Electronics: Current Status and Future Directions. Adv. Mater. 32, 1902387. doi:10.1002/ adma.201902387

Zhai, Z., Yan, W., Dong, L., Wang, J., Chen, C., Lian, J., et al. (2020). Multidimensional Materials with Layered Structures for Supercapacitors: Advanced Synthesis, Supercapacitor Performance and Functional Mechanism. Nano Energy 78, 105193. doi:10.1016/j.nanoen.2020.105193

Zhang, L., Liu, H., Wang, M., and Liu, W. (2006). Carbon Aerogels for Electric Double-Layer Capacitors. Rare Met. 25, 51-57. doi:10.1016/s1001-0521(07) 60044-8

Zhang, Y., Feng, H., Wu, X., Wang, L., Zhang, A., Xia, T., et al. (2009). Progress of Electrochemical Capacitor Electrode Materials: A Review. Int. J. Hydrogen Energ. 34, 4889-4899. doi:10.1016/j.ijhydene.2009.04.005

Zhang, L., Chen, X., Jin, S., Guan, J., Williams, C. T., Peng, Z., et al. (2014). Rapid Microwaves Synthesis of CoSix/CNTs as Novel Catalytic Materials for Hydrogenation of Phthalic Anhydride. J. Solid State. Chem. 217, 105-112. doi:10.1016/j.jssc.2014.05.021

Zhang, X., Xie, H., Liu, Z., Tan, C., Luo, Z., Li, H., et al. (2015). Black Phosphorus Quantum Dots. Angew. Chem. Int. Ed. 54, 3653-3657. doi:10.1002/ anie. 201409400

Zhang, L., DeArmond, D., Alvarez, N. T., Malik, R., Oslin, N., McConnell, C., et al. (2017). Flexible Micro-supercapacitor Based on Graphene with 3D Structure. Small 13, 1603114. doi:10.1002/smll.201603114

Zhang, H., Yao, M., Wei, J., Zhang, Y., Zhang, S., Gao, Y., et al. (2017). Stable $\mathrm{P} / \mathrm{n}$-Dopable Conducting Redox Polymers for High-Voltage Pseudocapacitor Electrode Materials: Structure-Performance Relationship and Detailed Investigation into Charge-Trapping Effect. Adv. Energ. Mater. 7, 1701063. doi:10.1002/aenm.201701063

Zhang, L., Chen, X., Li, C., Armbrüster, M., Peng, Z., and Liang, C. (2018). Cobalt Silicides Nanoparticles Embedded in N-Doped Carbon as Highly Efficient Catalyst in Selective Hydrogenation of Cinnamaldehyde. ChemistrySelect 3, 1658-1666. doi:10.1002/slct.201800007

Zhang, C., McKeon, L., Kremer, M. P., Park, S.-H., Ronan, O., Seral-Ascaso, A., et al. (2019). Additive-free MXene Inks and Direct Printing of Microsupercapacitors. Nat. Commun. 10, 1795. doi:10.1038/s41467-01909398-1
Zhang, Y., Wang, Y., Ganesh, A., Wang, G., Shi, X., Qiao, Y., et al. (2021) Engineered Electrode Structure for High-Performance 3D-Printed All-SolidState Flexible Microsupercapacitors. Adv. Eng. Mater. 23, 2100357. doi:10.1002/ adem.202100357

Zhao, H., and Lei, Y. (2020). 3D Nanostructures for the Next Generation of HighPerformance Nanodevices for Electrochemical Energy Conversion and Storage. Adv. Energ. Mater. 10, 2001460. doi:10.1002/aenm.202001460

Zhao, H., Liu, L., Vellacheri, R., and Lei, Y. (2017). Recent Advances in Designing and Fabricating Self-Supported Nanoelectrodes for Supercapacitors. Adv. Sci. 4, 1700188. doi:10.1002/advs.201700188

Zhao, H., Liu, L., Fang, Y., Vellacheri, R., and Lei, Y. (2018). Nickel Nanopore Arrays as Promising Current Collectors for Constructing Solid-State Supercapacitors with Ultrahigh Rate Performance. Front. Chem. Sci. Eng. 12, 339-345. doi:10.1007/s11705-018-1699-6

Zhao, H., Liu, L., and Lei, Y. (2018). A Mini Review: Functional Nanostructuring with Perfectly-Ordered Anodic Aluminum Oxide Template for Energy Conversion and Storage. Front. Chem. Sci. Eng. 12, 481-493. doi:10.1007/ s11705-018-1707-x

Zhao, M. Q., Trainor, N., Ren, C. E., Torelli, M., Anasori, B., and Gogotsi, Y. (2019). Scalable Manufacturing of Large and Flexible Sheets of MXene/Graphene Heterostructures. Adv. Mater. Technol. 4, 1800639. doi:10.1002/admt.201800639

Zhou, Y., Xu, H., Lachman, N., Ghaffari, M., Wu, S., Liu, Y., et al. (2014). Advanced Asymmetric Supercapacitor Based on Conducting Polymer and Aligned Carbon Nanotubes with Controlled Nanomorphology. Nano Energy 9, 176-185. doi:10.1016/j.nanoen.2014.07.007

Zhu, J., Xiao, G., and Zuo, X. (2020). Two-Dimensional Black Phosphorus: An Emerging Anode Material for Lithium-Ion Batteries. Nano-Micro Lett. 12, 120. doi:10.1007/s40820-020-00453-x

Zhu, T., Yang, Y., Liu, Y., Lopez-Hallman, R., Ma, Z., Liu, L., et al. (2020). Wireless Portable Light-Weight Self-Charging Power Packs by Perovskite-Organic Tandem Solar Cells Integrated with Solid-State Asymmetric Supercapacitors. Nano Energy 78, 105397. doi:10.1016/j.nanoen.2020.105397

Conflict of Interest: The authors declare that the research was conducted in the absence of any commercial or financial relationships that could be construed as a potential conflict of interest.

Publisher's Note: All claims expressed in this article are solely those of the authors and do not necessarily represent those of their affiliated organizations, or those of the publisher, the editors and the reviewers. Any product that may be evaluated in this article, or claim that may be made by its manufacturer, is not guaranteed or endorsed by the publisher.

Copyright (c) 2022 Sun, Chen, Liang, Zhi and Xue. This is an open-access article distributed under the terms of the Creative Commons Attribution License (CC BY). The use, distribution or reproduction in other forums is permitted, provided the original author(s) and the copyright owner(s) are credited and that the original publication in this journal is cited, in accordance with accepted academic practice. No use, distribution or reproduction is permitted which does not comply with these terms. 